\title{
Load partition and microstructural evolution during in situ hot deformation of Ti-6Al-6V-2Sn alloys
}

\author{
David Canelo-Yubero ${ }^{\mathrm{a}, \mathrm{b}, *}$, Guillermo Requena ${ }^{\mathrm{c}}$, Federico Sket ${ }^{\mathrm{d}}$, Cecilia Poletti ${ }^{\mathrm{a}}$, \\ Fernando Warchomicka ${ }^{a}$, John Daniels ${ }^{\mathrm{e}}$, Norbert Schell ${ }^{\mathrm{f}}$, Andreas Stark ${ }^{\mathrm{g}}$ \\ ${ }^{a}$ Graz University of Technology, Institute of Materials Science and Welding, Kopernikusgasse 24/I, 8010 Graz, Austria \\ ${ }^{\mathrm{b}}$ Vienna University of Technology, Institute of Materials Science and Technology, Karlsplatz 13/308, A-1040 Vienna, Austria \\ ${ }^{\mathrm{C}}$ German Aerospace Centre, Institute of Materials Research, Linder Höhe, 51147 Cologne, Germany \\ d IMDEA Materials Institute, C/Erik Kandel 2, Getafe, 28906 Madrid, Spain \\ e School of Materials Science and Engineering, UNSW Australia, Sidney 2052, Australia \\ ${ }^{\mathrm{f}}$ Structural Research on New Materials, Helmholtz-Zentrum Geesthacht Outstation at DESY, Hamburg, Germany \\ ${ }^{\mathrm{g}}$ Institute of Materials Research, Helmholtz-Zentrum Geesthacht, Max-Planck-Str. 1, 21502 Geesthacht, Germany
}

\section{A R T I C L E I N F O}

\section{Article history:}

Received 5 November 2015

Received in revised form

15 January 2016

Accepted 21 January 2016

Available online 22 January 2016

Keywords:

Titanium alloys

Synchrotron x-ray diffraction

Hot deformation

Load partition

Plasticity

Deformation mechanism

\begin{abstract}
A B S T R A C T
Two Ti-6Al-6V-2Sn alloys, with globular and lamellar microstructures, are deformed at $750{ }^{\circ} \mathrm{C}$ during tensile and compression tests. The lamellar microstructure shows softening and higher peak stress values than the globular microstructure as a consequence of the Hall-Petch effect. In-situ high energy synchrotron diffraction experiments allow characterization of the load partition between $\alpha$ - and $\beta$-phases, plastic deformation mechanisms and texture evolution. The $\alpha$-phase deforms mainly by rotation while the $\beta$-phase deforms by misorientation formation, acting merely as load transfer agent. The Taylor factor evolution of the $\alpha$-phase and the annihilation of dislocations are analyzed qualitatively and quantitatively. The Taylor factor is connected to both the softening observed in the alloy with the lamellar microstructure and the texture development.
\end{abstract}

(c) 2016 Elsevier B.V. All rights reserved.

\section{Introduction}

The microstructure of titanium alloys can be tailored applying thermo-mechanical treatments without modification of their chemical composition. As a consequence, a wide range of mechanical properties can be obtained [1]. The morphology, distribution and amount of allotropic phases play an important role for the elastic properties as well as for the plastic behaviour. Therefore, it is essential to determine the influence of the microstructural evolution during processing and service. Tensile/compression tests are common tools to characterize the macroscopic response of engineering materials at various temperatures and deformation rates. On the other hand, they do not provide information about load partition in multiphase materials, elastic anisotropies of crystallographic planes, etc., and cannot be used to study the deformation mechanisms taking place in the different allotropic phases. Therefore, these tests are usually combined with

\footnotetext{
* Corresponding author at: Institute of Materials Science and Welding, Graz University of Technology, Kopernikusgasse 24/I, A-8010 Graz, Austria.

E-mail address: david.caneloyubero@tugraz.at (D. Canelo-Yubero).
}

ex-situ microstructural characterization by additional techniques such as microscopy and electron backscatter diffraction (EBSD) as a function of temperature, strain rate and strain. Moreover, when titanium alloys are thermo-mechanically treated at high temperatures, samples can be hardly analyzed after cooling due to allotropic transformations that can alter the results [2].

During the last two decades, bulk diffraction techniques, i.e. high energy synchrotron x-ray diffraction (HEXRD) and neutron diffraction (ND), were developed allowing in situ characterization of material behaviour. Both techniques offer high penetration compared to laboratory $\mathrm{x}$-rays sources and short acquisition times down to below one second for HEXRD and a few minutes for ND. In-situ HEXRD allows the determination of average elastic lattice strains of crystalline phases [3-6] together with deformation/restoration mechanisms [7] and texture evolution during thermomechanical processes.

Several studies in different titanium alloys were carried out at room temperature by means of in situ HEXRD to determine the response of different crystallographic planes under tensile/compression strains [8-16]. Elastic-Plastic Self-Consistent (EPSC) models were also considered to simulate the behaviour of these 
crystallographic planes upon the same tensile or compression loading [10-16]. Specifically, it was shown that the allotropic hexagonal close-packed (hcp) $\alpha$-phase and the body-centred cubic (bcc) $\beta$-phase are capable of bearing different portions of loads during continuous deformation [10,12]. Furthermore, and also by means of the HEXRD experiments, the Rietveld method has been successfully used to calculate the evolution of crystallographic texture during different stages of a rolling process [11,17]. DebyeScherrer rings depicted as timelines for individual crystallographic planes contributed to determine not only lattice orientation but also the specific dynamic mechanism of restoration of each phase in

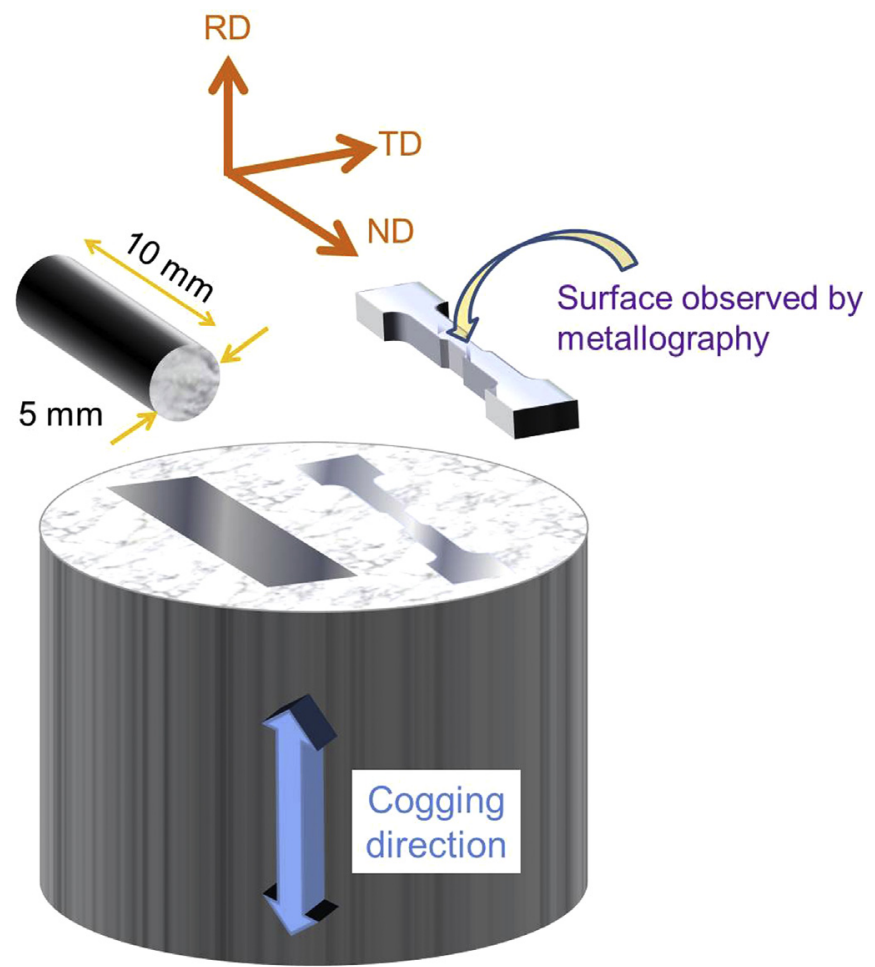

Fig. 1. Schematic representation of the ingot metallurgy alloy indicating the surface observed by metallographic characterization and the samples for the in situ HEXRD experiments during tensile (dogbone sample) and compression (cylindrical sample) tests. Rolling (RD), normal (ND) and transverse (TD) directions plotted at the top correspond to the same system used for the pole figures. Cogging direction is indicated. Samples are not scaled.
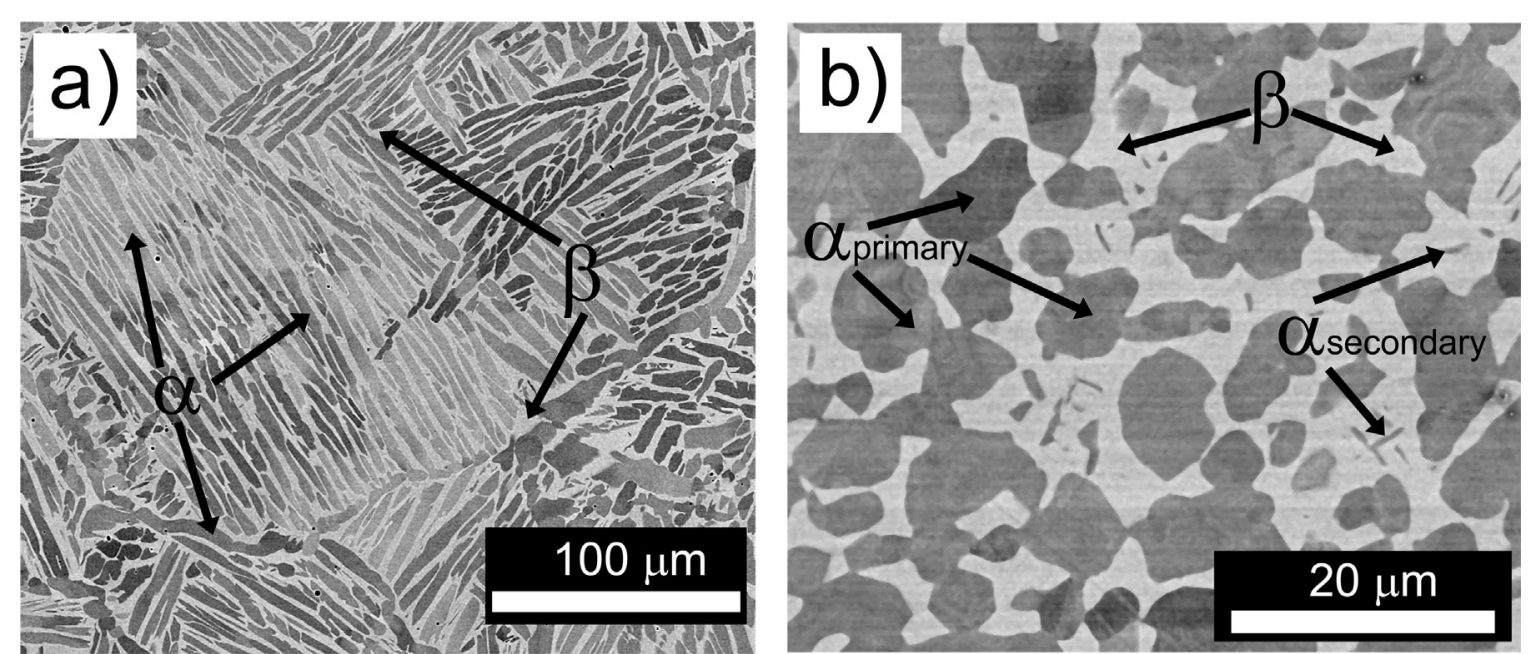

Fig. 2. SEM micrographs (BSE mode) of the alloys heat treated at $750{ }^{\circ} \mathrm{C}$ and water quenched: a) Ti662 PM, b) Ti662 IM. titanium aluminide alloys during thermo-mechanical processes [7].

Among all titanium alloys, the most widely used and investigated is the $\alpha+\beta$ Ti-6Al-4V (Ti64). Understanding the deformation behaviour at high temperatures of $\alpha$-lamellar and globular- $\alpha$ microstructures is of crucial importance to design proper thermo-mechanical treatments. The flow curves of these alloys are characterized by a peak stress at low strains followed by softening [18-22]. The softening observed during hot compression tests from $815^{\circ} \mathrm{C}$ to $955{ }^{\circ} \mathrm{C}$ (strain rates from $0.001 \mathrm{~s}^{-1}$ to $10 \mathrm{~s}^{-1}$ ) for a lamellar microstructure was attributed to the cooperative $\alpha$ lamellae rotation, kinking and bending towards orientations with low Taylor factor ("softer" orientations) and/or slip transmission across the $\alpha / \beta$ interfaces. Optical and SEM (scanning electron microscopy) micrographs were mostly used to observe these processes. Additionally, the initial Taylor factor was calculated by means of simulations when the influence of the Hall-Petch needed to be quantified [18]. The $\beta$-phase seemed to play a secondary role during the softening process of these alloys.

Ti-6Al-6V-2Sn (Ti662) is a modification of the Ti64 alloy, that contains larger amount of $\beta$-phase and its service temperature is raised up to $315^{\circ} \mathrm{C}$ due to the addition of Sn [23]. Previous macroscopic characterizations after hot compression at different strain rates (from $0.01 \mathrm{~s}^{-1}$ to $15 \mathrm{~s}^{-1}$ ) and temperatures (from $650{ }^{\circ} \mathrm{C}$ to $950{ }^{\circ} \mathrm{C}$ ) are reported in [24]. For strain rates $\leq 0.15 \mathrm{~s}^{-1}$, the globular- $\alpha$ microstructure and the $\alpha$-lamellae exhibited steady state and softening at $750{ }^{\circ} \mathrm{C}$, respectively. Nevertheless, more detailed analyses, mainly from a crystallographic point of view are required to determine the deformation phenomena during thermo-mechanical tests. The goals of the present work are to follow and describe the crystallographic lattice evolution of both $\alpha$ - and $\beta$ phases in Ti662 alloys with globular and lamellar microstructures during hot deformation. Therefore, in situ HEXRD experiments during both tensile and compression tests are carried out at $750{ }^{\circ} \mathrm{C}$ to determine the load partition between $\alpha$ - and $\beta$-phases and elucidate their plastic deformation mechanisms. Moreover, the Taylor factor and the annihilation of dislocations are analyzed and tracked during the experiments aiming at quantifying their influence during the softening of the lamellar microstructure.

\section{Methodology}

\subsection{Materials}

Ti662 alloys produced by two different processing routes were 
investigated: ingot metallurgy (IM) and powder metallurgy (PM). The IM alloy was obtained by cogging a cast bar up to $77 \mathrm{~mm}$ of diameter at temperatures just below the $\beta$-transus temperature $\left(T_{\beta} \sim 945{ }^{\circ} \mathrm{C}\right)$ [24]. Annealing at $885^{\circ} \mathrm{C}$, water quenching, aging at $540{ }^{\circ} \mathrm{C}$ and air cooling completed the thermal treatment. Cold and Hot Isostatic Pressing process (CHIP) was utilized to produce the PM alloy with the following steps: i) blending of powders, ii) cold isostatic pressing to obtain a "green" preform, iii) sintering of the "green" preform in a vacuum furnace with controlled heating and cooling rates and iv) hot isostatic pressing to produce a fully dense material [25].

Scanning electron microscopy (SEM) was used to study the microstructures before hot deformation. For this purpose, one sample of each material was held at $750{ }^{\circ} \mathrm{C}$ during $30 \mathrm{~min}$ in argon atmosphere with subsequent water quenching to freeze the microstructures. Samples were cut transversally to the cogging direction for metallographic characterization as indicated in Fig. 1. The microstructure of the PM alloy (Fig. 2a) consists of colonies of $\alpha$-lamellae embedded within the prior $\beta$-grains. The IM material is characterized by primary $\alpha$-grains oriented in the cogging direction (pre-forging process) showing a globular structure surrounded by a fine $\beta$-grain structure (see Fig. 2 b) with $\sim 1$ vol\% of secondary $\alpha$-needles.

\subsection{Hot deformation tests}

In-situ angle dispersive HEXRD experiments were performed in transmission mode during hot deformation. Data was acquired using 2-D (flat panel) detectors. Tensile and compression tests were carried out at strain rates of $0.0025 \mathrm{~s}^{-1}$ and $0.0015 \mathrm{~s}^{-1}$, respectively, at $750{ }^{\circ} \mathrm{C}$ in protective atmosphere. Before deformation, the samples were held during $30 \mathrm{~min}$ at test temperature to stabilize the microstructure (Fig. 2). Table 1 summarizes the experimental parameters at the different synchrotron beamlines: ID15B beamline of the European Synchrotron Radiation Facilities (ESRF), Harwi-II [26] at Doris III-Deutsches Elektronen-Synchrotron (DESY) and P07-HEMS beamline at PETRA III-DESY.

Tensile tests were carried out with a screw-driven Instron electro-thermo-mechanical tester (ETMT) [7] until fracture. The sample gauge length of $5 \mathrm{~mm}$ was designed short with respect to the sample length $(40 \mathrm{~mm})$ to avoid the use of extensometers. Although the stiffness of the machine is involved in the macrostrain values, it was assumed to be negligible. The beam was positioned at the centre of the sample below a spot-welded thermocouple. The experimental setup is shown schematically in Fig. $3 a$.

The compression tests were carried out in a Bähr dilatometer
DIL 805 equipped with an induction heating system and a deformation unit. The synchrotron beam reached the sample at $1.5 \mathrm{~mm}$ below a thermocouple spot-welded on its surface and at $3.5 \mathrm{~mm}$ from one side of the sample. A detailed schematic setup is shown in Fig. 3b.

A capillary with $\mathrm{LaB}_{6}$ powders was used to calibrate the sample-detector distances and the instrumental broadening.

\subsection{Strain and stress analysis}

The 2D diffraction images were integrated using the software
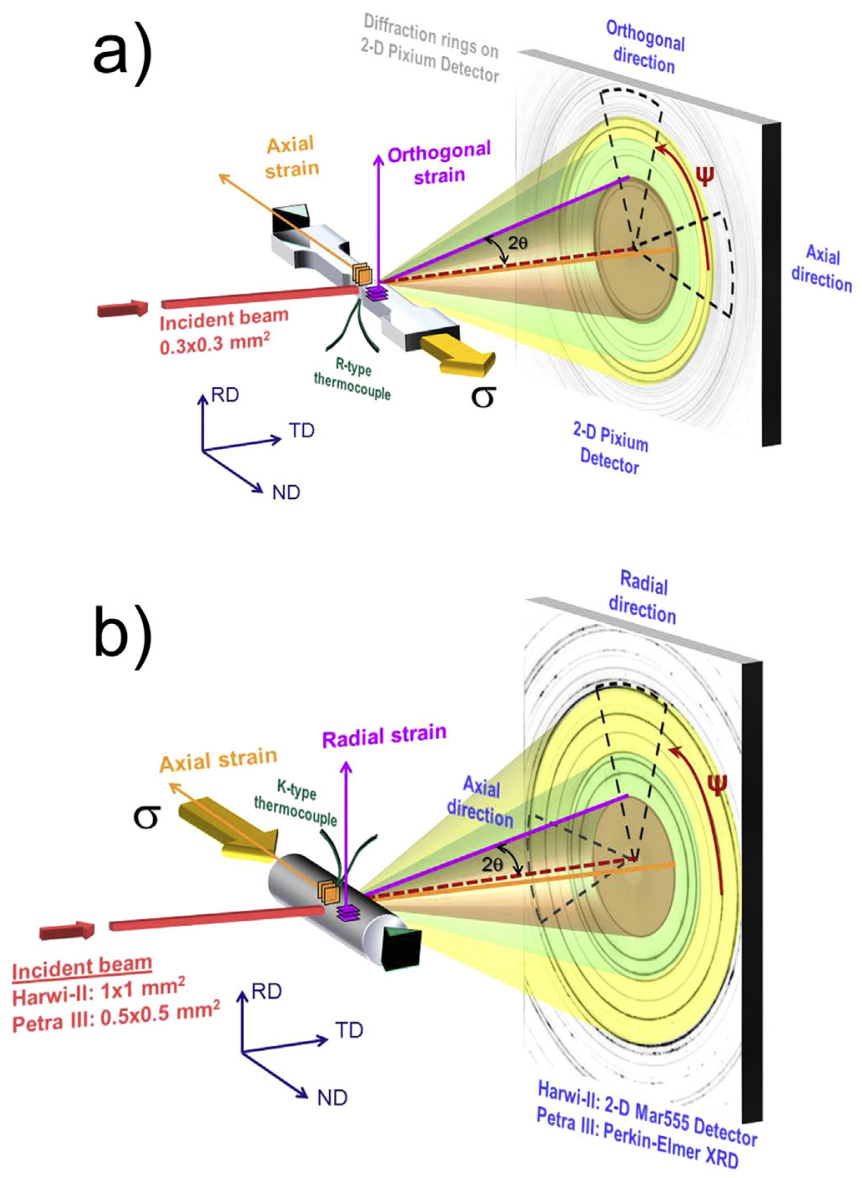

Fig. 3. Schematic view of the in situ HEXRD experiments during a) tensile tests at the ID15B beamline of ESRF and b) compression tests at Harwi-II/Petra III (Desy).

Table 1

Experimental parameters for in situ HEXRD tensile and compression tests carried out at different synchrotron beamlines.

\begin{tabular}{|c|c|c|c|}
\hline Alloy & Ti662 IM \& Ti662 PM & Ti662 PM & Ti662 IM \\
\hline Beamline & ID15B-ESRF & P07-Petra III DESY & Harwi-II-DORIS III DESY \\
\hline Acquisition time (sec/frame) & $\sim 0.7$ & $\sim 0.5$ & $\sim 4$ \\
\hline 2-D detector/Pixels & Pixium & Perkin-Elmer XRD 1622 & Mar555 \\
\hline Detector size $(\mathrm{H}) \times(\mathrm{V})$ & $2640 \times 1920$ & $2048 \times 2048$ & $2560 \times 3072$ \\
\hline Gauge volume $\left(\mathrm{mm}^{3}\right)$ & $0.3 \times 0.3 \times 1.5$ & $0.5 \times 0.5 \times 5$ & $1 \times 1 \times 5$ \\
\hline Sample-detector distance (mm) & 1043 & 1922 & 1534 \\
\hline Thermo-mechanical tester & ETMT & \multirow{3}{*}{\multicolumn{2}{|c|}{$\begin{array}{c}\text { Bähr } 805 \text { dilatometer } \\
\mathrm{K} \\
\text { Induction coil }\end{array}$}} \\
\hline Thermocouple type & $\mathrm{R}$ & & \\
\hline Heating system & DC through the sample & & \\
\hline Atmosphere & Argon & Helium & Helium \\
\hline
\end{tabular}


Fit2D [27], obtaining plots of $2 \theta$ against intensity. Cake portions of $10^{\circ}$ and $15^{\circ}$ (only for the compressive deformation of the IM alloy) were selected for the axial and the orthogonal/radial directions to obtain a high peak-to-background intensity ratio in the diffractograms (Fig. 3). The diffraction peaks were fitted individually with simple Voigt functions. Volume averaged elastic strains were calculated in the axial and orthogonal/radial directions considering the shift in the position of the diffraction peak of the corresponding $\{h k l\}$ crystallographic plane:

$\varepsilon_{i}=\frac{d_{i}-d_{0}}{d_{0}}=-\left(\theta_{i}-\theta_{0}\right) \cot \theta_{0}$

where $\varepsilon_{i}$ is the strain at deformation step $i, d_{i}$ and $d_{0}$ are the interplanar distances for the deformation step $i$ and the reference conditions determined with the Bragg's law [4], while $\theta_{i}$ and $\theta_{0}$ are the diffraction angles for the deformation step $i$ and the reference conditions, respectively. The $d$ value obtained after 30 min soaking at $750{ }^{\circ} \mathrm{C}$, before deformation, was chosen as $d_{0}$ and $\theta_{0}$ for the $\alpha$ and $\beta$-reflections. Therefore, the strain evolution during deformation was analyzed from an incremental point of view.

The evolution of the deviatoric stresses using the methodology proposed in [28] was applied to avoid misinterpretation of stress evolution owing to the lack of an absolute stress-free reference condition:

$\sigma_{1}-\sigma_{3}=-\frac{E}{(1+\nu)}\left(\theta_{1}-\theta_{3}\right) \cot \theta_{0}$

$\sigma_{2}-\sigma_{3}=-\frac{E}{(1+\nu)}\left(\theta_{2}-\theta_{3}\right) \cot \theta_{0}$
$\sigma_{1}-\sigma_{2}=-\frac{E}{(1+\nu)}\left[\left(\theta_{1}-\theta_{3}\right)-\left(\theta_{2}-\theta_{3}\right)\right] \cot \theta_{0}$

The stresses in the axial direction are indicated by $\sigma_{1}$, while those corresponding to the orthogonal/radial directions are $\sigma_{2}$ and $\sigma_{3}$. The $\theta_{0}$ angle corresponds to the scattering angle at the beginning of the tensile/compression tests, either in axial or in orthogonal/radial directions, since the influence in the final stress difference is negligible. To simplify the calculations, a cylindrical symmetry is assumed for both types of samples. Thus, $\sigma_{2}=\sigma_{3}$ and, therefore, Eq. (4)=Eq. (2), while Eq. (3)=0.

The Young's modulus $E$ and the Poisson's ratio $\nu$ of each crystallographic plane were considered to compute the deviatoric stresses in $\alpha$ and $\beta$. These elastic constants were assumed to have a temperature dependence similar to that of the macroscopic Young's modulus for the $\alpha$-phase between RT and $750{ }^{\circ} \mathrm{C}$ [29], while a linear dependence was assumed from RT [30] up to $1000{ }^{\circ} \mathrm{C}$ [31] for the $\beta$-phase. Values for different crystallographic planes of the $\alpha$-phase at RT were calculated using the program XEC by Wern [32] based on the Kröner model [33]. Since no data are available at RT for the $\beta$-phase, those corresponding to the $\beta$ titanium alloy Ti-28V were used because this alloy exhibits the closest vanadium content to the $\beta$-phase at $750{ }^{\circ} \mathrm{C}$, i.e. $\sim 13 \mathrm{wt} \%$ [1].

\subsection{Texture analysis}

Least-squares Rietveld refinement was carried out using the software MAUD [34] for quantitative phase analysis and texture evolution. An E-WIMV algorithm [35] was used to evaluate the texture evolution of the IM alloy during tensile and compressive

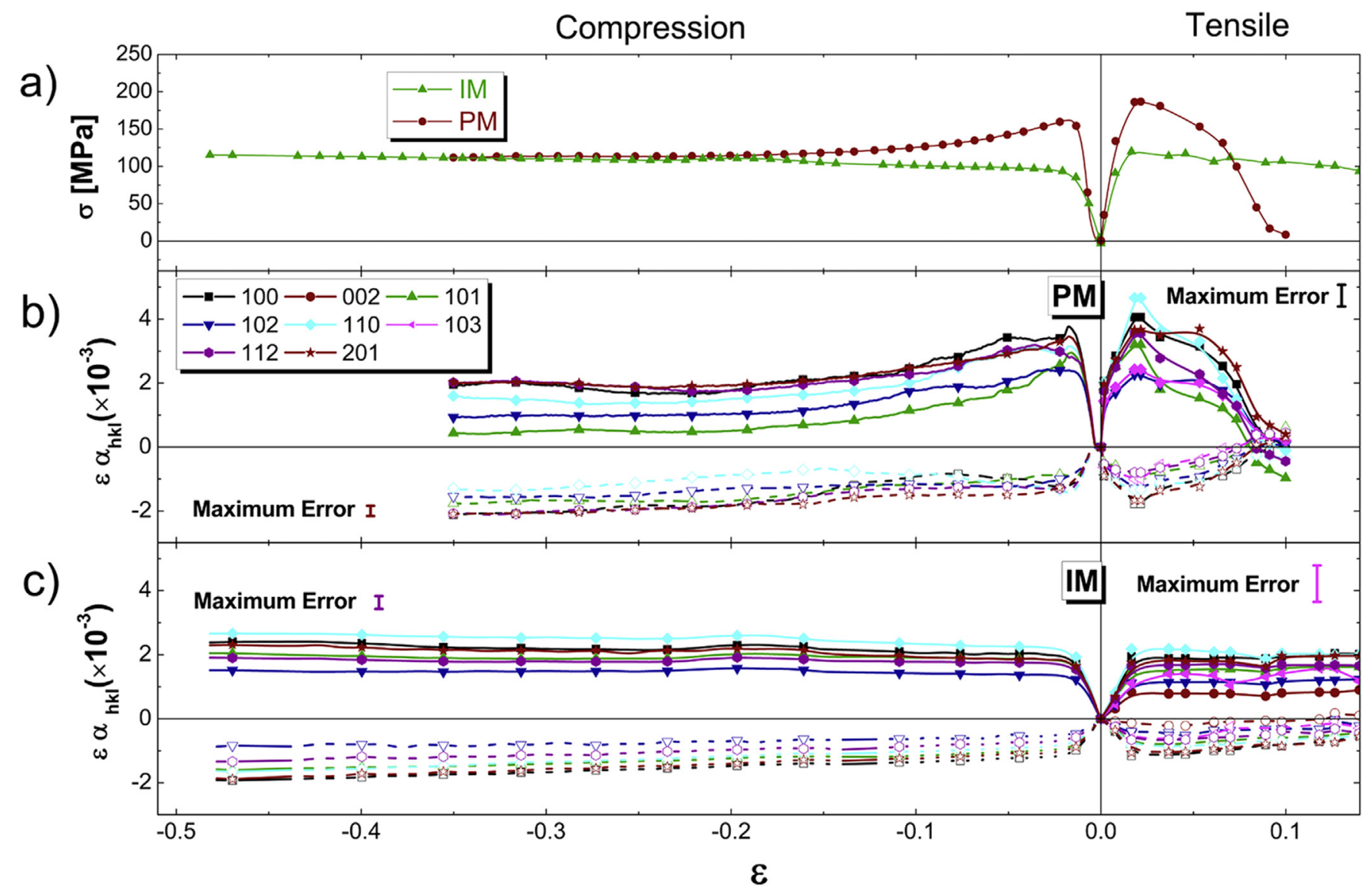

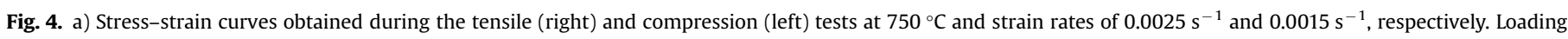

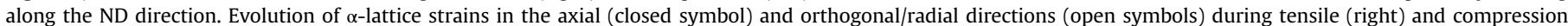
loading (left) for b) PM and c) the IM alloys. 


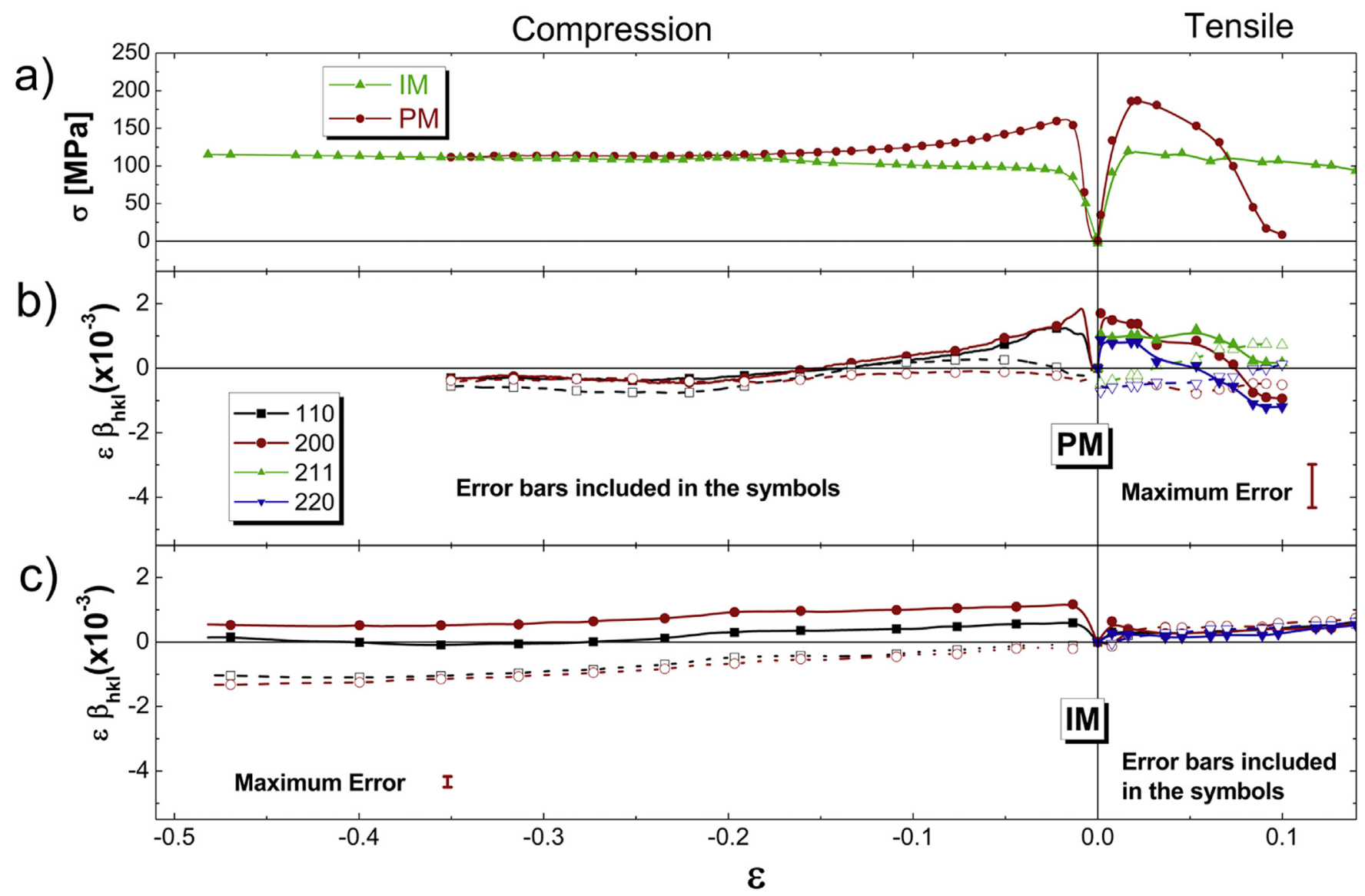

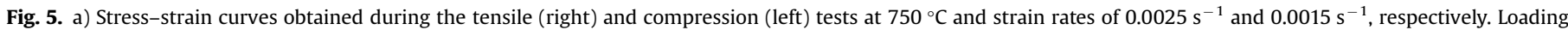

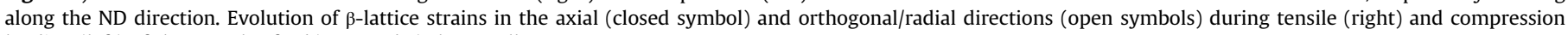
loading (left) of the samples for b) PM and c) the IM alloys.

deformation and only during compression for the PM material.

\subsection{Microstructure evolution during deformation}

The evolution of the Debye-Scherrer rings acquired during hot deformation was analyzed using a methodology analogous to that reported in [36]. The processing was carried out using Image [37] and the steps are summarized briefly: i) sequential stacking of consecutive diffraction images, ii) selection of the diffraction ring corresponding to one crystallographic plane with subsequent transformation into Cartesian coordinates resulting in a 3-D volume with axes $2 \theta, \varepsilon$ and $\psi$, iii) intensity sum and projection over the $\varepsilon-\psi$ plane. The final representation corresponds to the evolution during deformation of grains oriented matching the Ewalds's sphere in reciprocal space.

\section{Results}

\subsection{Macroscopic true stress-strain curves}

The macroscopic true stress-strain curves are shown in Figs. 4a and $5 \mathrm{a}$ for the tensile (right) and compression (left) tests. Rietveld refinements show approximately constant volume fractions of $\alpha$ and $\beta$-phases within the small gauge volume during deformation, i.e., $65 \mathrm{vol} \%$ and $\sim 71 \mathrm{vol} \%$ for the $\alpha$-phase of the IM and PM alloys, respectively ( $\beta$-phase balanced). The PM alloy exhibits higher peak stress than the IM material, i.e. $185 \mathrm{MPa}$ for the tensile test and $160 \mathrm{MPa}$ for the compression. The maximum strength for the IM alloy during tensile loading is about $120 \mathrm{MPa}$, while this stress is reached at the end of the compression test. The IM alloy exhibits a slight strain hardening during the compression test, while the PM alloy reaches a steady state at $\varepsilon \sim-0.16$ after a period of softening. The strain to failure of the PM alloy is significantly smaller than that of the IM alloy.

\subsection{Elastic strains during deformation}

Axial (closed symbols) and orthogonal/radial (open symbols) strains are shown for the $\alpha$ - and $\beta$-phases in Figs. $4 b, c$ and $5 b, c$, respectively, under tensile (right) and compressive (left) deformation. For the sake of readability, the indicated error bars correspond to the upper limit for all phases and they were obtained for the crystallographic plane with identical colour. Only the strains for crystallographic planes with errors allowing a sensible analysis are shown. Also, the following convention is adopted to compare the results of all experiments: axial strains are shown with positive values, while orthogonal/radial with negative values for both types of loading conditions.

The $\alpha$-strains for the IM alloy (Fig. 4c) in axial direction show an increase with approximately constant slope for the tensile and compression tests as deformation proceeds until an absolute strain of 0.02 . Although the strain values of the different crystallographic planes are to a large extent covered by the error bars, a trend in increasing order can be inferred: $\alpha-002, \alpha-102 \approx \alpha-103, \alpha$ $101 \approx \alpha-112, \alpha-201 \approx \alpha-100$ and, finally, $\alpha-110$ with an absolute value of $\sim 2.1 \times 10^{-3} \pm 2.4 \times 10^{-4}$ for both types of deformation. The strains for the tensile test remain constant after the maximum external stress while they tend to follow the hardening behaviour of the macroscopic curve during compressive deformation. The PM 


\section{Tensile}

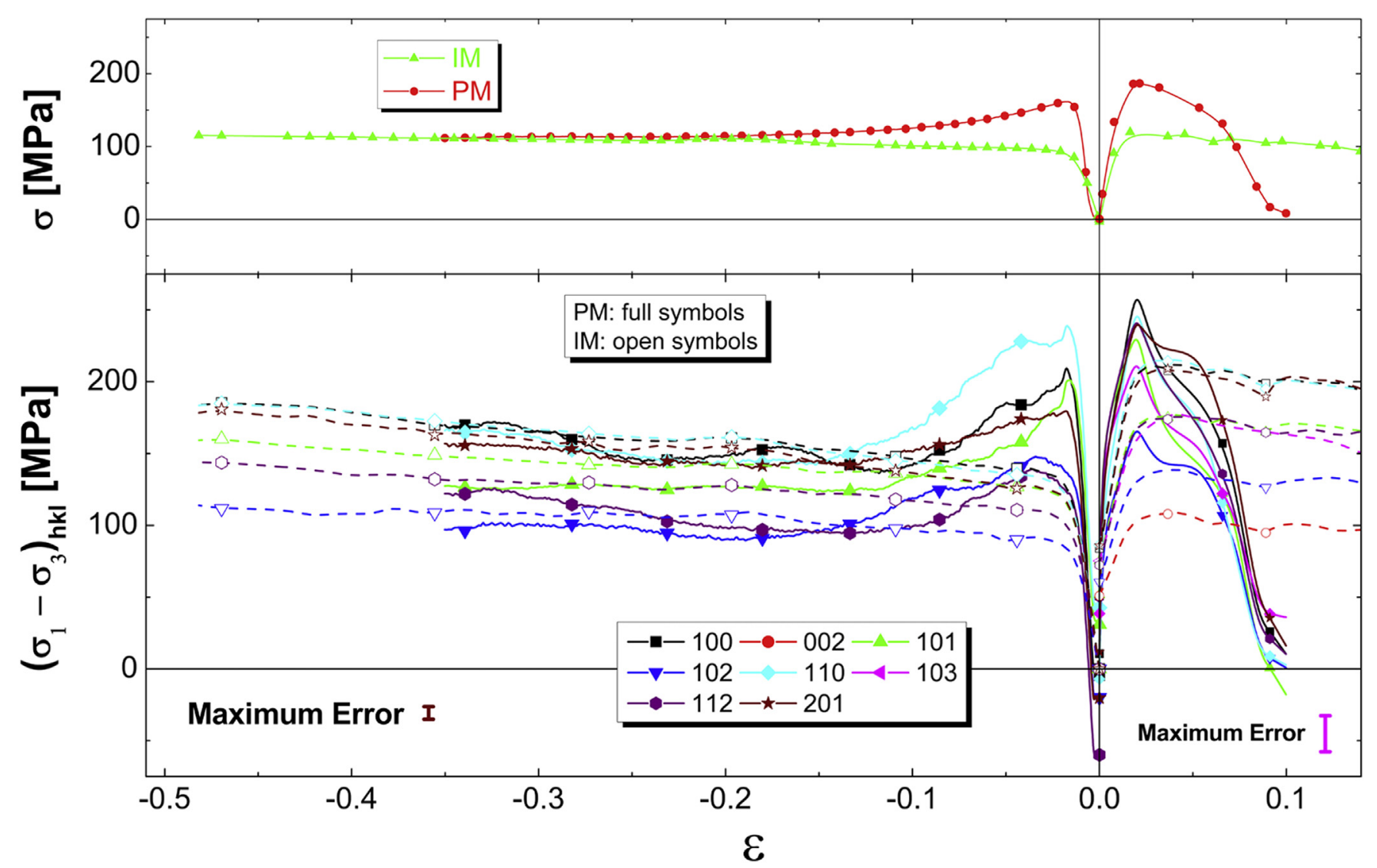

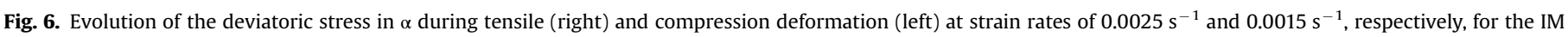
(open symbols) and PM (full symbols) alloys. Loading along the ND direction.

alloy (Fig. 4b) also shows for both tensile and compression tests an increase of $\alpha$-strains until a maximum macroscopic stress is reached at an absolute strain of 0.02 . Then, the $\alpha$-strains reproduce the strain softening behaviour exhibited by their macroscopic $\sigma-\varepsilon$ curves. The $\{h k l\}$ sequence of maximum strains for both types of tests is practically the same as for the IM alloy and final strains for tensile loading are approximately at the same level as those observed at beginning of deformation.

In the orthogonal/radial direction (open symbols) all the strains for both IM and PM alloys are compressive during tensile deformation and tensile during compression owing to the Poisson's effect. They reach the highest values at maximum external stress during the tensile tests, with subsequent decrease as the deformation proceeds. During compressive deformation, the strains show some hardening for $|\mathcal{E}|>0.02$.

The $\beta$-phase in the IM and PM materials (Fig. 5b and c) reaches maximum interplanar strains in the early stages of the experiment, i.e. the strains evolve from an elastic to a plastic regime above $\sim 100 \mathrm{MPa}$ for the IM alloy and $\sim 50 \mathrm{MPa}$ for the PM alloy. The maximum $\beta$-strain for the PM alloy is $\sim 2 \times 10^{-3}$ for $\beta-200$. Beyond the peak stress, the axial strains become approximately zero at 0.16 of absolute strain during compressive deformation. These final strain values are even $\leq 0$ for tensile loading. The orthogonal/radial strains for the PM alloy remain close to zero during both tests. The $\beta$-strains for the IM alloy are close to zero in both directions during the tensile test and $\beta-200$ exhibits a maximum value of $\sim 1 \times 10^{-3}$ during compressive deformation with a subsequent reduction in both axial and radial directions. Above an absolute strain of $0.3, \beta$-strains are $\sim 0$ in the axial direction and $\sim-1 \times 10^{-3}$ in the radial direction.

The deviatoric stresses can be seen in Figs. 6 and 7 for different crystallographic planes of $\alpha$ - and $\beta$-phases, respectively. Their evolution follows the macroscopic $\sigma-\varepsilon$ curves for tensile (right) and compression (left) tests. The greater deviatoric stresses at the peak stress for the $\alpha$-phase corresponds to the PM alloy in both tensile and compression tests.

\subsection{Microstructural evolution during deformation}

The evolution of three $\alpha$ - and two $\beta$-reflections during deformation is shown from Figs. 8-10 for the PM alloy. The macroscopic $\sigma-\varepsilon$ curves are plotted to correlate microstructural changes with the deformation behaviour of the alloy. The azimuthal angles $\psi=90^{\circ}$ and $\psi=270^{\circ}$ correspond to the axial (A) direction, while $\psi=0^{\circ}, \psi=180^{\circ}$ and $\psi=360^{\circ}$ to the orthogonal $(\mathrm{O}) /$ radial $(\mathrm{R})$ direction. Since the small grain size of the IM material compared to the gauge volume does not allow identifying the evolution of individual diffraction spots during deformation (continuous Debye-Scherrer rings), these plots are omitted in this work.

Fig. 8 shows the evolution of the PM alloy during tensile deformation. The initial diffraction pattern at $\varepsilon=0$ depicts only a few diffraction spots representing grains with specific orientations. These spots of high intensity evolve in the form of high intensity narrow bands (dark) as deformation proceeds. These bands remain roughly vertical and constant in width for all the $\alpha$ - and $\beta$-planes until the ultimate tensile strength is reached at $\sim 185 \mathrm{MPa}$. For $\varepsilon>\sim 0.02$, some of the $\alpha$-bands change continuously their position 


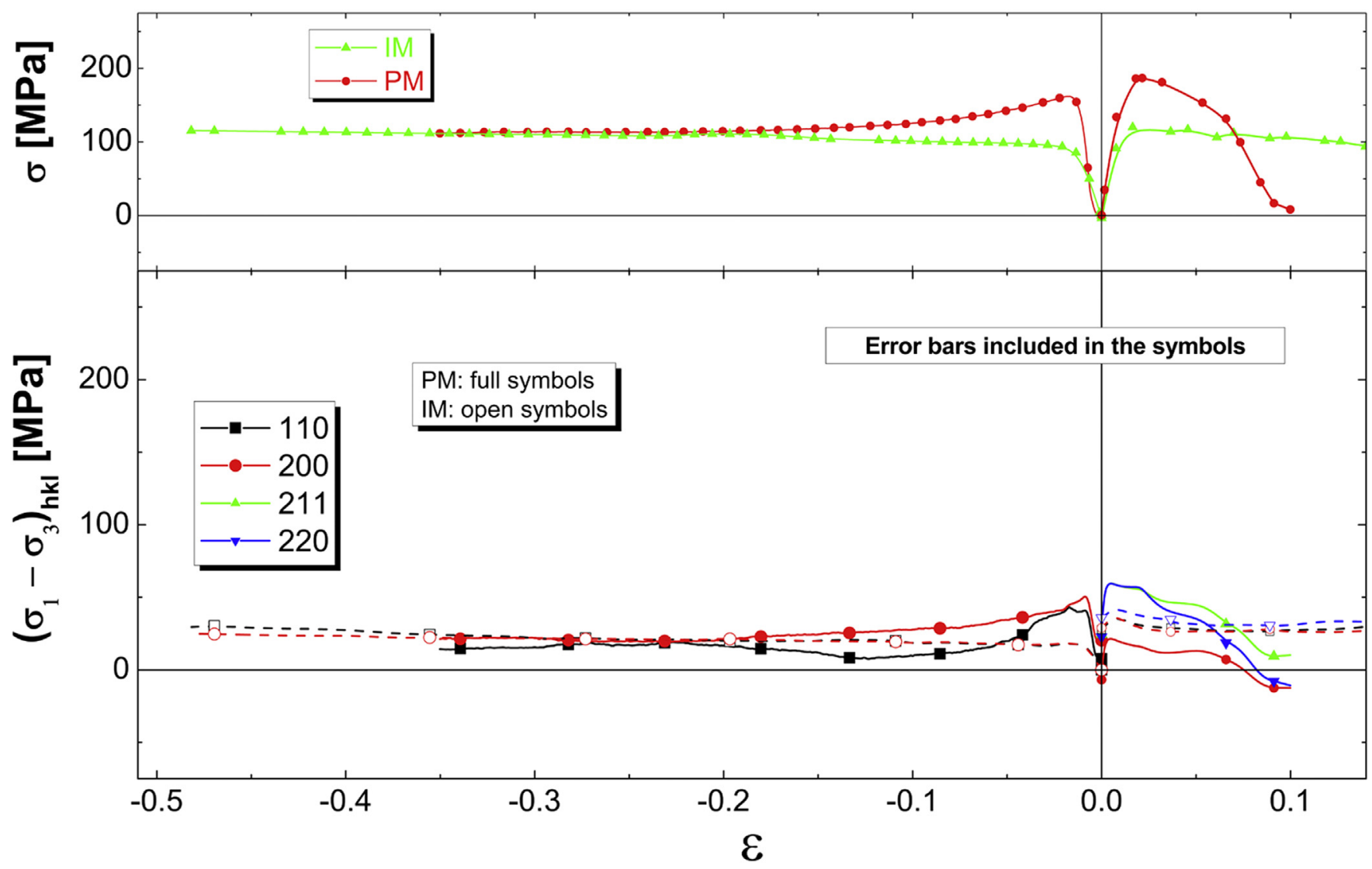

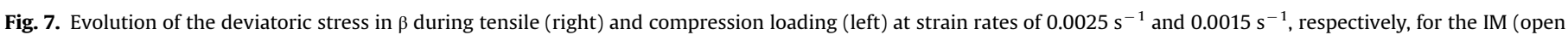
symbols) and PM (full symbols) alloys. Loading along the ND direction.

along the $\psi$-axis with no apparent preferred direction, resulting in inclined bands. Furthermore, some diffraction bands become wider and, as a consequence, the overall intensity distribution becomes more homogeneous along $\psi$. The diffraction bands take a vertical orientation with a constant width for an absolute strain larger than 0.07 , indicating no further evolution of the microstructure. At the end of the experiment, the intensity is more homogeneously distributed along $\psi$ than before deformation. The bands corresponding to the $\beta$-planes spread changing their spotty distribution into a pattern with more homogeneous intensity distribution along $\psi$ for $\varepsilon>\sim 0.02$. Identically to the $\alpha$-planes, this process is active until $\varepsilon \sim 0.07$.

Fig. 9 shows the evolution of the PM alloy during compression up to the maximum strain obtained for tensile deformation. Compared to the tensile results, there is a larger number of diffraction spots owing to the larger gauge volume (see Table 1). Therefore, the evolution of single diffraction spots is harder to follow. The complete $\psi-\varepsilon$ evolution up to an absolute strain of 0.35 is shown in Fig. 10. Above $|\varepsilon| \sim 0.10$, the $\alpha$-bands merge and only continuous regions with different intensities along $\psi$ are observed. Regions with higher intensity are distinguished around the radial direction of $\alpha-002$ at the end of the compression test, indicating that the basal planes tend to orient parallel to the load direction. Furthermore, high intensity regions are also observed for $\alpha-100$ in azimuthal angles surrounding the axial direction. They seem to reach maximum values at $\sim \pm 30^{\circ}$ with respect to the load direction.

\subsection{Texture evolution}

The Rietveld analysis was carried out with the same 2D diffraction images utilised for the strain calculation and consequently no additional sample rotation was imposed for the texture analysis. Therefore, only information from RD and ND is available originating a level of artefact close to the TD since no symmetry was applied. The $R_{w n b}$ values (quality factor with background subtracted, i.e., only peak contribution) range between $9.4 \%$ and $11.5 \%$ for the IM alloy and between $10.5 \%$ and $15.5 \%$ for the PM alloy. Reconstructed texture plots are shown from Figs. 11-13 for a plane perpendicular to the load direction (ND), with the logarithmic intensity scale in m.r.d. (multiples of a random distribution) valid simultaneously for both $\alpha$ - and $\beta$-phases.

\subsubsection{Ingot metallurgy alloy}

The texture in as received condition ( $\sigma=0 \mathrm{MPa}, \varepsilon=0$ ) is shown in Fig. 11 for the tensile deformation. It reveals an initial alignment of $\alpha-002$ mainly parallel to $\mathrm{RD}$, with two poles along TD and higher intensities in the upper region delimited between $\sim 0^{\circ}$ and $+45^{\circ}$ with respect to ND. The prismatic reflection $\alpha-100$, oriented perpendicularly to $\alpha-002$, shows two poles in RD indicating an alignment parallel to the ND-TD plane. Moreover, two more $\alpha-100$ poles are distinguished, both of them compatible with the orientation observed for $\alpha-002$. The plastic tensile deformation affects the orientation distribution of the $\alpha$-phase since the microstructure evolves aligning the $c$-axis between $\sim 0^{\circ}$ and $-45^{\circ}$ with respect to the ND and finally giving rise to four well-defined poles in the $\alpha-100$ reconstructed figure. The $\beta$-phase exhibits initial 110 texture perpendicular to RD. $\beta$ undergoes small texture variations 


\section{PM - Tensile}

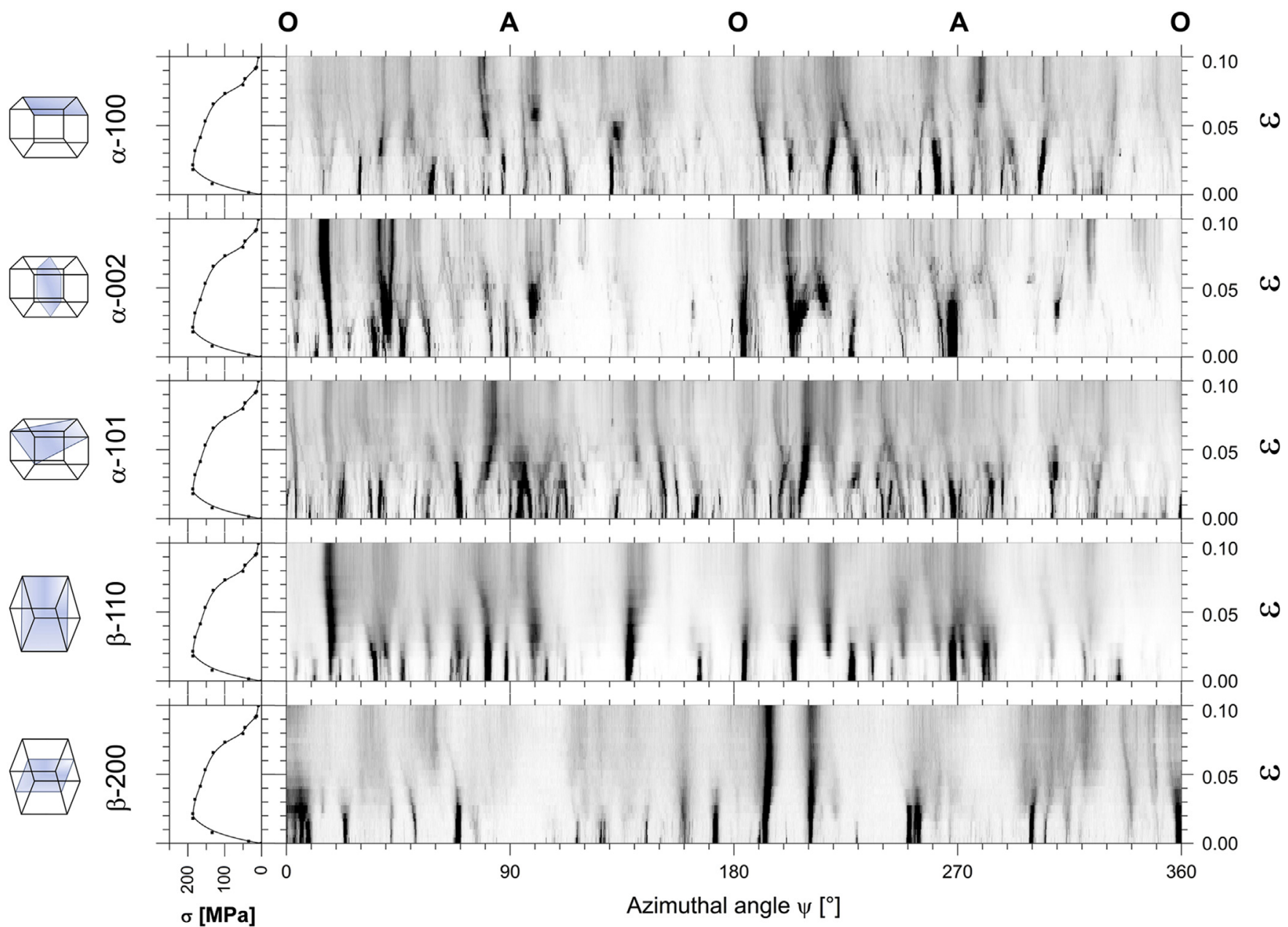

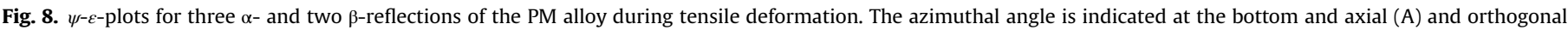
(O) directions at the top. The plot on the left side corresponds to the macroscopic $\sigma$ vs. $\varepsilon$ curve.

during the tensile deformation. During compressive deformation (see Fig. 12) the initial preferred orientation also shows an alignment of $\alpha-002$ parallel to RD with two poles in TD, similar to the observed during tensile deformation, while the prismatic plane $\alpha$ 100 exhibits two poles in RD. $\beta$ differs with a 200 dominating orientation at $\varepsilon=0$. As compressive deformation increases, $\alpha-100$ evolves orienting along $\mathrm{RD}$, while $\beta$-200 develops a more marked preferred orientation.

\subsubsection{Powder metallurgy}

The PM alloy develops a marked texture in the $\alpha$ - and $\beta$-phases during compressive deformation as it is shown in Fig. 13 (Rietveld refinements are hindered at $\varepsilon=0$ because of the large $R_{w n b}$ ). At I $\varepsilon \mid \sim 0.16$, no evidence of preferred orientation is observed for the $\alpha$ phase, although some poles start to appear for $\alpha-002$. On the contrary, the $\beta$-phase shows at this stage an alignment of $\beta-200$ perpendicular to TD. During subsequent stages of compressive deformation $\alpha-002$ aligns preferentially parallel to the external load as can it be inferred from both $\alpha-100$ and $\alpha-002$ pole figures. The $\beta$-phase evolves into a more marked 001 texture at $|\mathcal{E}| \sim 0.35$.

\section{Discussion}

The differences observed in the peak stress for the same alloy during tensile and compression tests may be related to the strain rate variation. Nevertheless, the peak stress difference $\Delta \sigma$ between the PM and IM alloys for the same deformation type remains constant at $\sim 65-70 \mathrm{MPa}$. The higher peak stress for the PM alloy is attributed to the Hall-Petch effect as analyzed in [18] for a Ti64 alloy with both colony- $\alpha$ and globular microstructures. Based on Refs. [38,39], $\Delta \sigma$ can be expressed as:

$\Delta \sigma=M_{P M}\left(\tau_{P M}+K_{s} \times l_{P M}^{-1 / 2}\right)-M_{I M}\left(\tau_{I M}+K_{s} \times l_{I M}^{-1 / 2}\right)$

in which $\tau_{i}$ denotes the resolved shear stress, $M_{i}$ is the Taylor factor, $K_{s}$ is the Hall-Petch constant at the test temperature and $l_{P M}$ and $l_{I M}$ represent the lamellar width and the grain size for the PM and IM alloy, respectively. When the initial textures are similar for both alloys, Eq. (5) can be simplified [18] as the following:

$\Delta \sigma=M \times K_{s} \times\left(l_{P M}^{-1 / 2}-l_{I M}^{-1 / 2}\right)$

$M$ and $K_{s}$, values extrapolated from [18] for a strain-rate of $0.1 \mathrm{~s}^{-1}$, are 3 and $0.0326 \mathrm{MPa} \sqrt{ } \mathrm{m}$, respectively. The lamellar width $l_{P M}$ is $\sim 4.2 \mu \mathrm{m}$ and the grain size $l_{I M} \sim 6.2 \mu \mathrm{m}$, both calculated from micrographs. Eq. (6) yields $\Delta \sigma \sim 18 \mathrm{MPa}$ which is an underestimation of the observed $\Delta \sigma \sim 65-70 \mathrm{MPa}$. It must be taken into account that the grain size $l_{I M}$ can be affected by a non fully fragmentation of the lamellae during the previous thermo-mechanical process (cogging), as observed in Fig. 2b and by EBSD 


\section{PM - Compression}

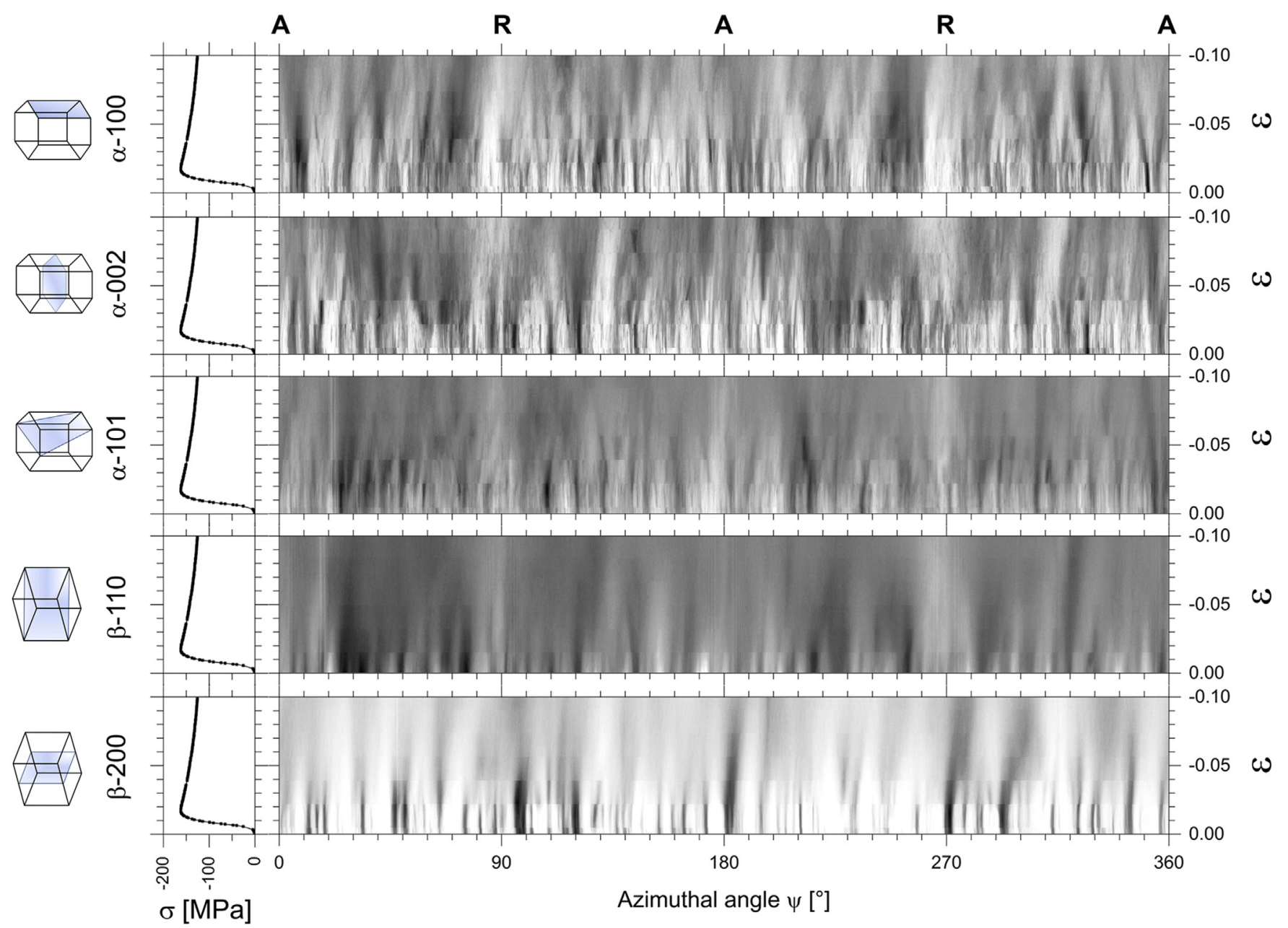

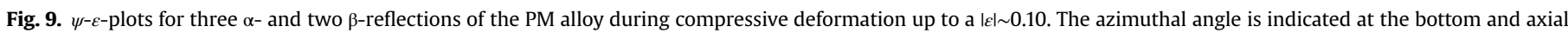
(A) and radial (R) directions at the top. The plot on the left side corresponds to the macroscopic $\sigma$ vs. $\varepsilon$ curve.

measurements in a Ti64 alloy [40], giving rise to larger grain size. Nevertheless, this variation cannot explain alone the observed $\Delta \sigma$. Therefore, the simplified Eq. (6) is not suitable for this study and the different Taylor factors and resolved shear stresses for each alloy need to be calculated in Eq. (5) to explain the observed $\Delta \sigma$.

The calculated deviatoric stresses represent a valuable help when a stress-free reference cannot be determined experimentally. A previous work [10] showed for a Ti64 alloy during tensile loading at room temperature that prismatic planes of the $\alpha$-phase bear a higher portion of load than the others and $\alpha-102$ is the first to yield, in agreement with the results of the present work for both alloys (Fig. 6). The greater deviatoric stresses at the peak stress for the $\alpha$-phase correspond to the PM alloy in both tensile and compression tests. The initial random orientation of the lamellae in the PM alloy and the large size of the $\alpha$-colonies, compared to the original $\beta$-grain size (50-400 $\mu \mathrm{m}$ [24]) provoke a small number of the former favourably oriented for slip glide. Consequently, the Taylor factor in the PM is larger compared to the IM alloy which shows a more favourable $\alpha$-grain orientation for activation of basal and prismatic $<\mathrm{a}>$ systems [18] as a consequence of the initial texture resulting from the cogging. As a result, the $\alpha$-phase is capable to accommodate more load in different planes in the PM alloy. The $\beta$-phase plays a secondary role in the final strength [18], as observed with the deviatoric stresses (Fig. 7), acting only as load transfer agent as can be deduced from its early stage plastification and small values, differing in small quantities for both PM and IM alloys.

The Azimuthal-Strain (AS)-plots show valuable information related to the deformation mechanisms for both $\alpha$ - and $\beta$-phases of the PM alloy (Figs. 8-10). The $\beta$-phase deforms mainly with formation of crystallographic misorientation (Fig. 14a and b) leading to the subgrain formation $[2,41]$. The $\alpha$-phase undergoes mainly grain rotation (Fig. 14c-f) up to $|\varepsilon| \sim 0.06$ since the bands corresponding to the initial diffraction spots modify their azimuthal angle with no preferred orientation and keep their width roughly constant. Above this value, misorientation is summed up to the rotation (see magnified region in Fig. 14c). This deformation mechanism was reported by Liss et al. [7] during hot compression of titanium aluminide alloys with globular $\alpha$-grains. The vanishing of some bands occurs when the grains do not match the Ewald's sphere in the reciprocal space owing to both their rotation and the material flow during plastic deformation. The grain rotation observed during the in situ HEXRD experiments in the $\alpha$-phase is a combination of the geometrical reorientation of the lamellae orthogonally to the load direction [42,43] and crystallographic rotation within the lamellae $[42,44]$ in order to fulfil geometrical requirements of the imposed strain [42].

No evidence of dynamic recrystallization was revealed by the AS-plots for the colony- $\alpha$ microstructure since no popping up and disappearance of reflections is observed according to Liss et al. 
PM - Compression

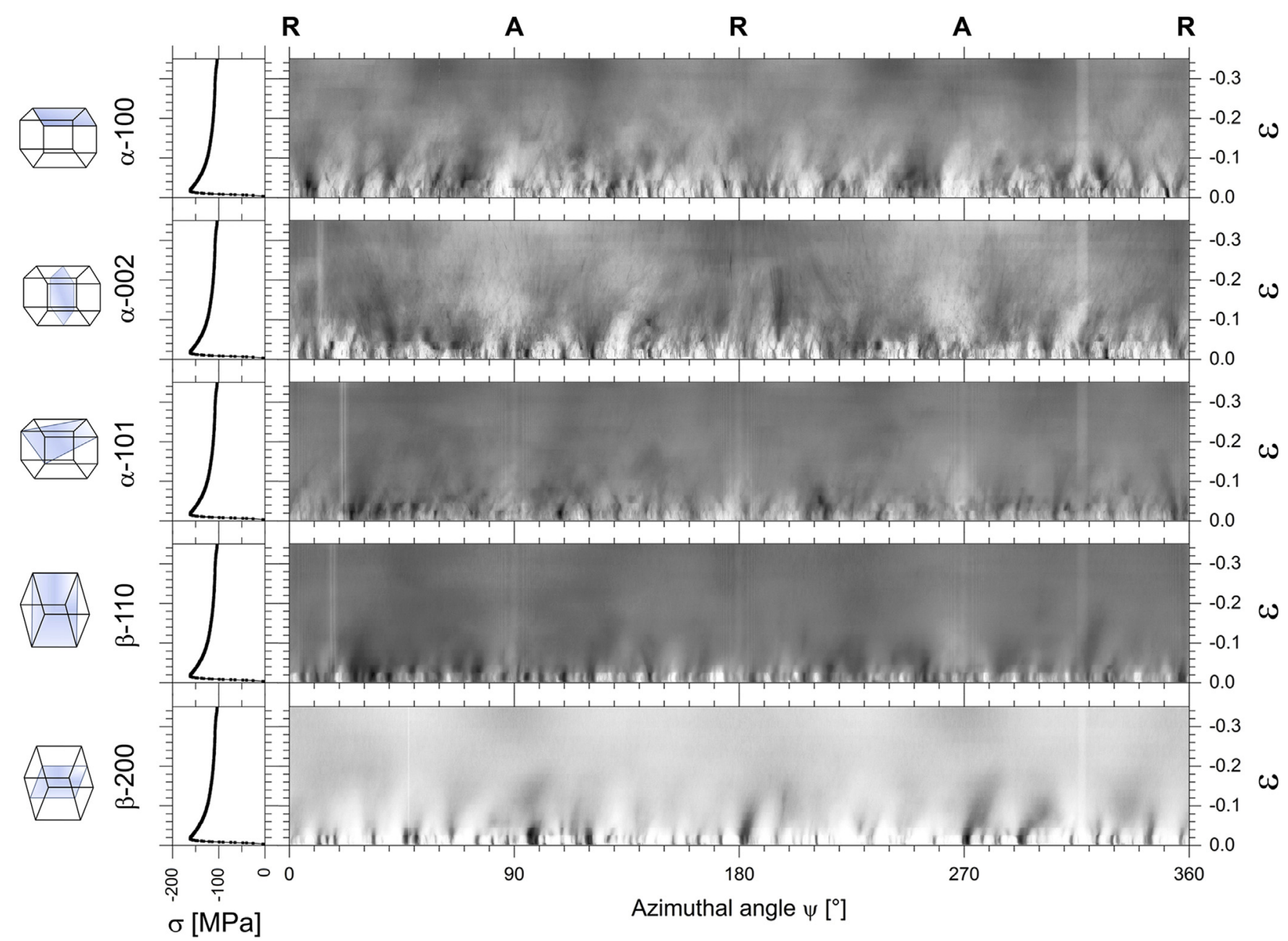

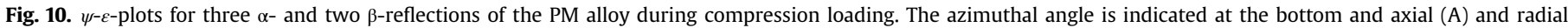
(R) directions at the top. The plot on the left side corresponds to the macroscopic stress vs. strain curve.

[45]. This agrees with dynamic processes observed for a similar alloy during compression tests at strain rate of $0.001 \mathrm{~s}^{-1}$ and strains larger than 0.7 [44].

The Taylor factor, $M$, can be approached using the intensity of diffraction peaks corresponding to the crystallographic $\alpha$-planes, i.e. those playing the primary role. The intensity is associated to the volume fraction of lamellae oriented in different directions. Therefore, the following expression is used to evaluate $M$ only for the axial direction:

$M(\varepsilon)=\sum_{i=1}^{n} \frac{1 / m_{(h k l)_{i}} \times I_{(h k l)_{i}}}{\sum_{i=1}^{n} I_{(h k l)_{i}}}$

where $n$ is the number of $\alpha$-diffraction peaks analyzed, $m$ is the Schmid factor of each family of crystallographic planes (obtained from [46]) and $I$ represents their respective intensities. The Taylor factor variation as a function of the strain is illustrated in Fig. 15 for both PM and IM alloys during the compression tests. $M$ decreases as deformation increases for the PM alloy while the IM alloy exhibits a constant value. The initial values yield $\sim 3.9$ for the PM alloy and $\sim 3.7$ for the IM alloy at $\varepsilon=-0.02$ (Fig. 15c). These values differ from those calculated in [18] and used in Eq. (6), although it must be taken into account that this is a lower-bound and that the initial textures are different. The resolved shear stresses for each alloy can be calculated as $\sigma / M$. Recalculating Eq. (5) for the observed $\Delta \sigma=65 \mathrm{MPa}$ :

$65=3.9 \times\left[41+K_{s} \times\left(4.2 \times 10^{-6}\right)^{-1 / 2}\right]-3.7 \times\left[26+K_{s} \times\left(6.2 \times 10^{-6}\right)^{-1 / 2}\right]$

$K_{s}$ is $0.00312 \mathrm{MPa} \sqrt{ } \mathrm{m}$. This value is close to that assumed before in Eq. (6) and validates the calculated $M_{P M}$ and $M_{I M}$ by Eq. (7).

The overall reduction of the Taylor factor from $|\mathcal{E}| \sim 0.02$ to । $\varepsilon \mid \sim 0.35$ for the PM alloy is $20 \%$ whereas the peak stress reduction at the same strains is $\sim 30 \%$. This decrease of $M$ can be explained taking into account the texture evolution, as observed in Fig. 13. During compression, the $\alpha$-lattice rotates aligning $\alpha-002$ parallel to the load direction. This indicates that the resolved shear stress for $\alpha-002$ equals zero and, therefore, no basal $<\mathrm{a}>$ slip is activated. On the other hand, the prismatic planes $\alpha-100$ align at more plastically favourable orientations during deformation (see pole figures at the left of Fig. 13) and a larger number of crystallites tend to orient so that prismatic $<\mathrm{a}>$ slip, with the lowest critical resolved shear stress, activates.

Dislocations form and annihilate in both phases during plastic deformation. The analyzed parameter that is associated to dislocations is the full width at the half-maximum (FWHM) of the diffraction peaks [5]. Fig. 16 shows its variation for the PM alloy during the compression tests in normalized (Fig. 16c) and absolute values (Fig. 16b) up to $|\varepsilon|=0.125$. The normalized values facilitate the comparison of all diffraction peaks according to the following expression [47]: 


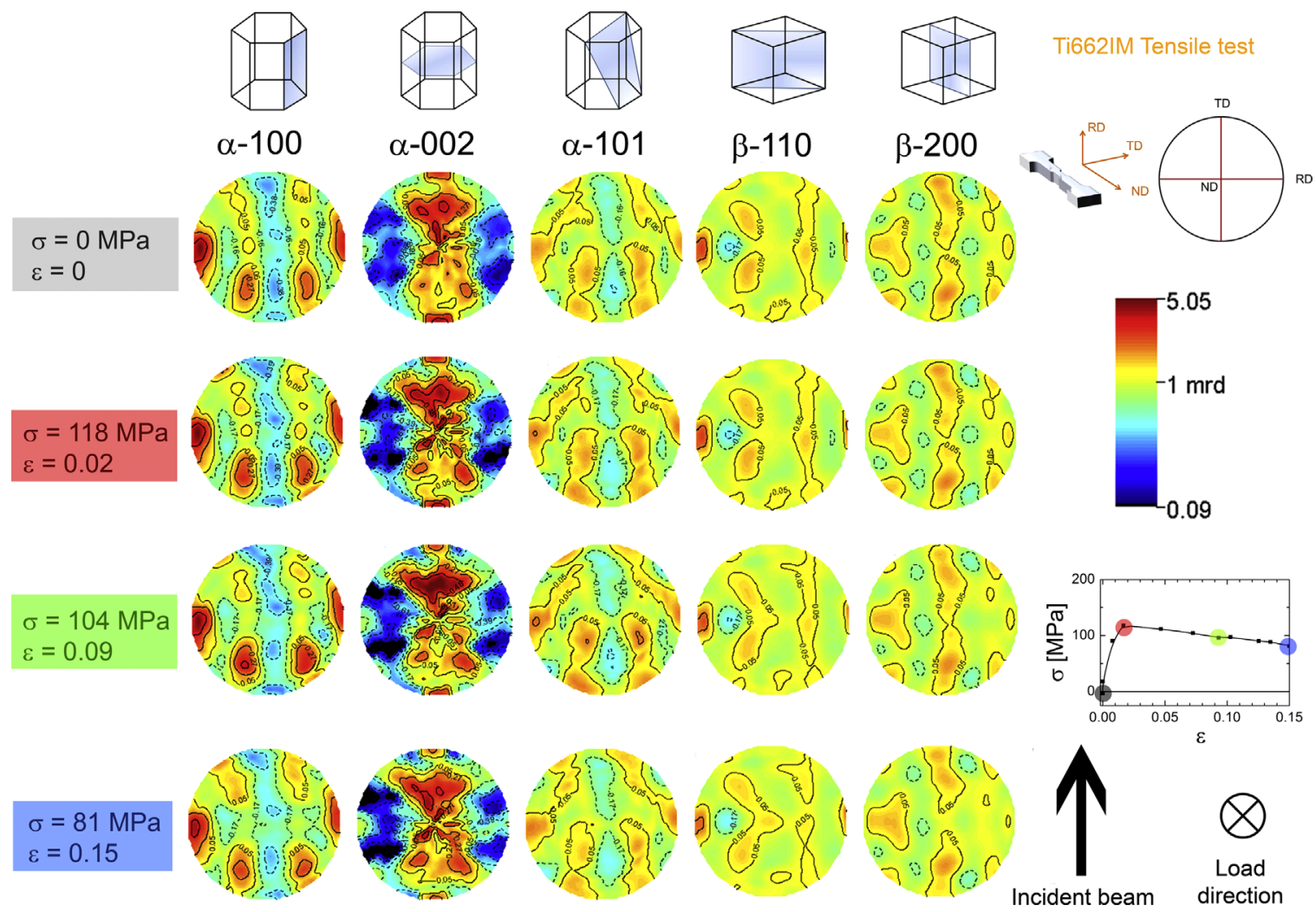

Fig. 11. $\alpha$ and $\beta$ pole figures reconstructed from the in situ HEXRD experiments at different tensile deformation stages of the IM alloy. The load direction is orthogonal to the plane of the pole figure. The logarithmic m.r.d. scale and $\sigma$ vs. $\varepsilon$ curve are shown on the right.

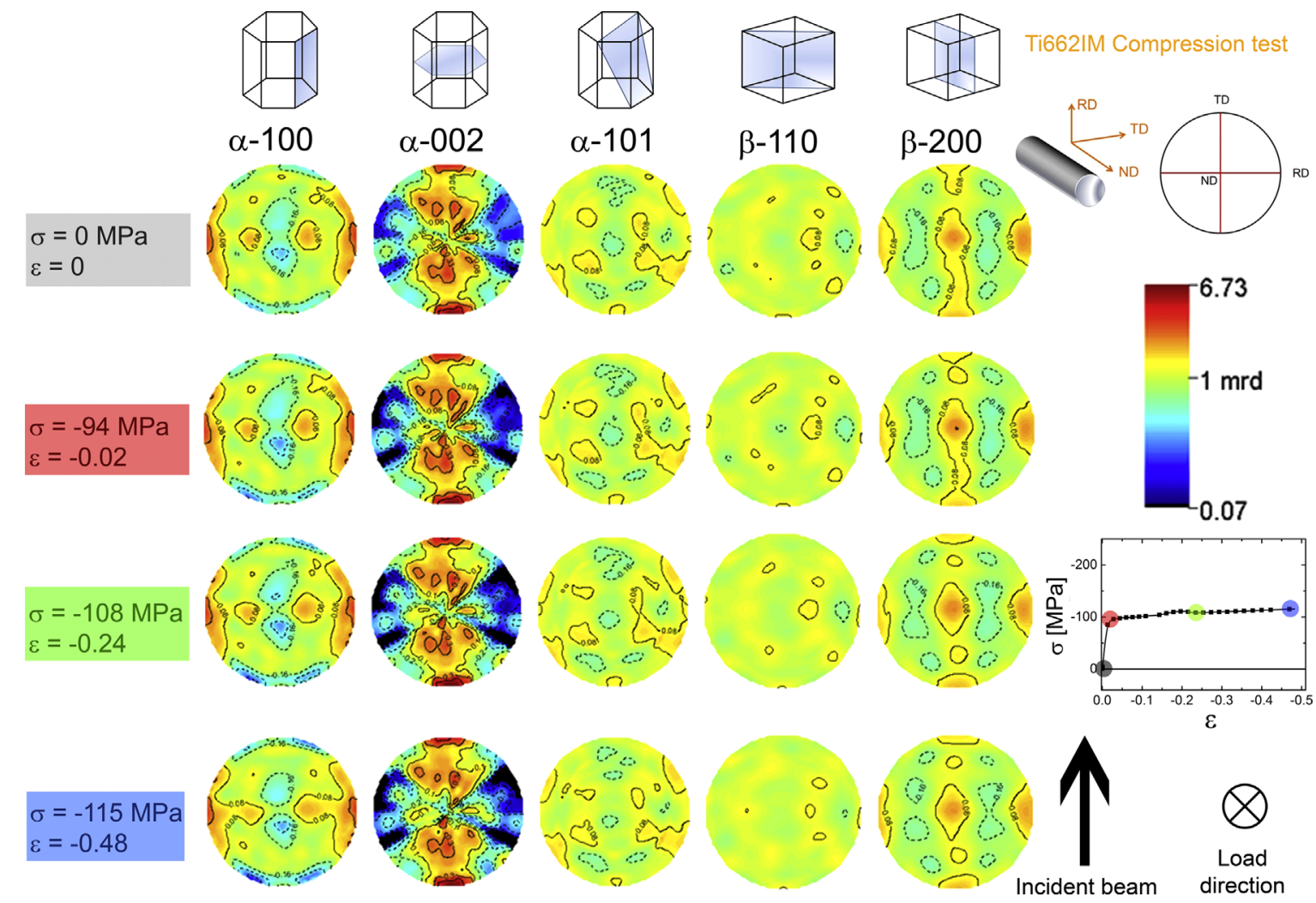

Fig. 12. $\alpha$ and $\beta$ pole figures reconstructed from the in situ synchrotron experiments at different compressive deformation stages of the IM alloy at $750{ }^{\circ} \mathrm{C}$. The load direction is orthogonal to the plane of the pole figure. The logarithmic m.r.d. scale and $\sigma$ vs. $\varepsilon$ curve are shown on the right. 


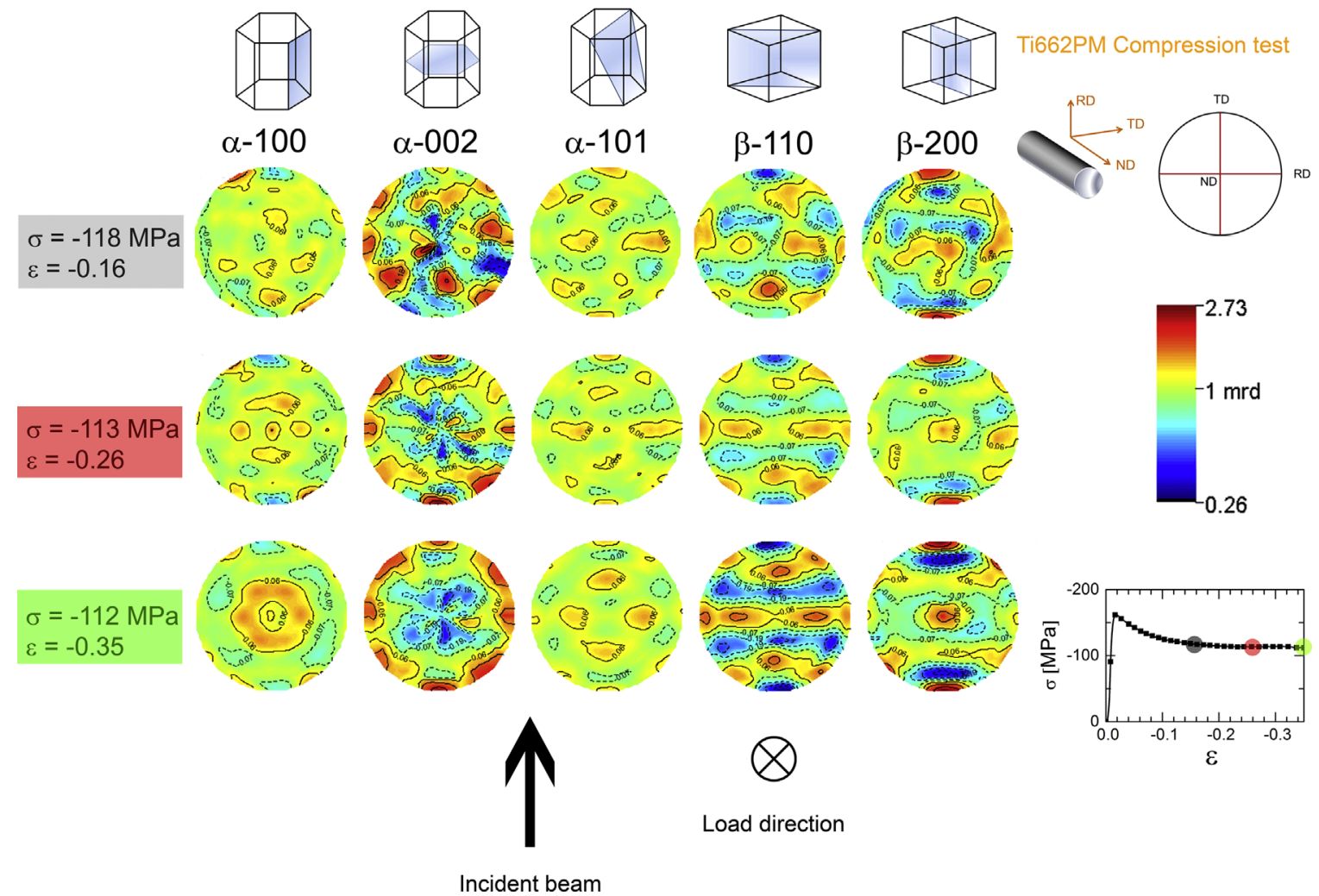

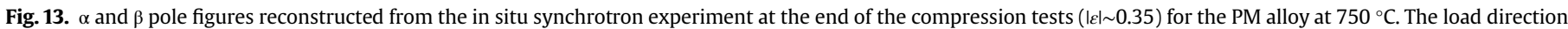
is orthogonal to the pole figure plane. The contours are in logarithmic units. The logarithmic scale is also visible on the right.

a)

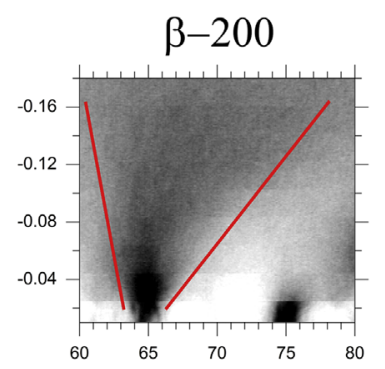

d)

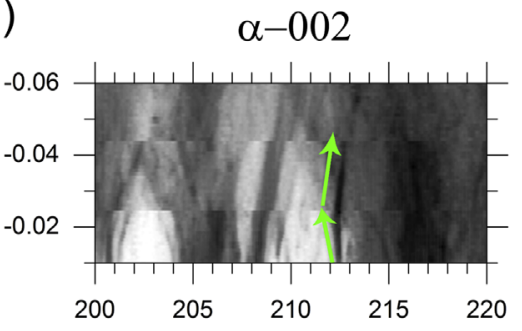

b)

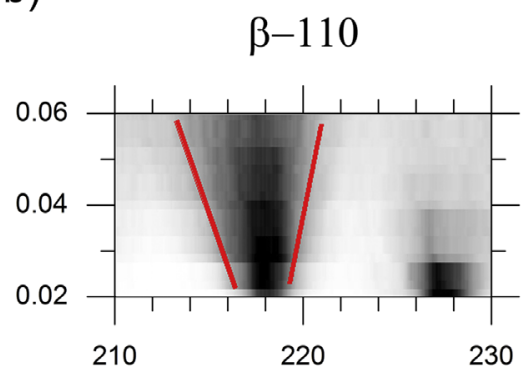

e)

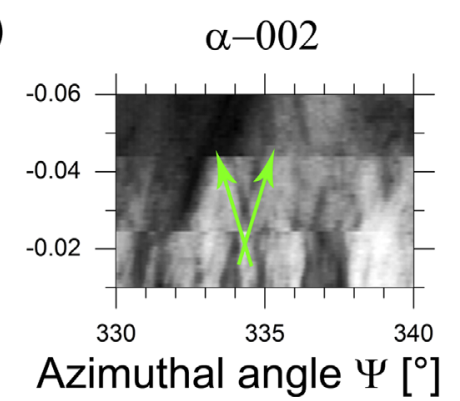

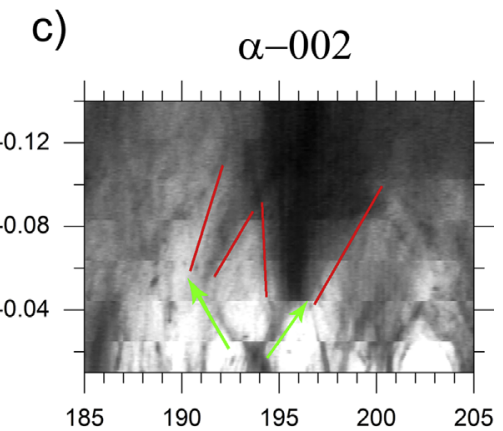

f) $\alpha-110$

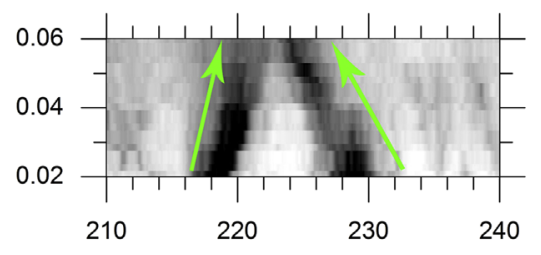

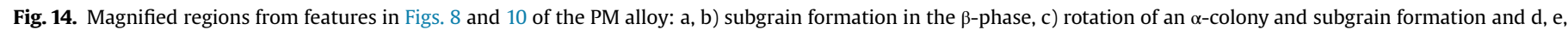
f) $\alpha$-grain rotation with different rotation angles.

$$
F_{N}(\varepsilon)=\frac{F(\varepsilon)-F_{\min }}{F_{\max }-F_{\min }}
$$

where $F_{N}(\varepsilon)$ denotes de normalized FWHM, $F(\varepsilon)$ is the measured value and $F_{\min }$ and $F_{\max }$ are the minimum and maximum values, respectively, for each analyzed $\alpha$-plane. A reduction is observed after the maximum stress for $\alpha-110$ and $\alpha-101$. Semiatin et al. [18] suggested that one soft $<\mathrm{a}\rangle$ and one hard $<\mathrm{a}>$ system would be favourably oriented to be activated during softening, in our case the prismatic $\alpha-110$ (soft) and the pyramidal $\alpha-101$ (hard). It should be borne in mind that not only the dislocation density but also the crystallite size contribute to the FWHM and it is complex 


\section{Compression}

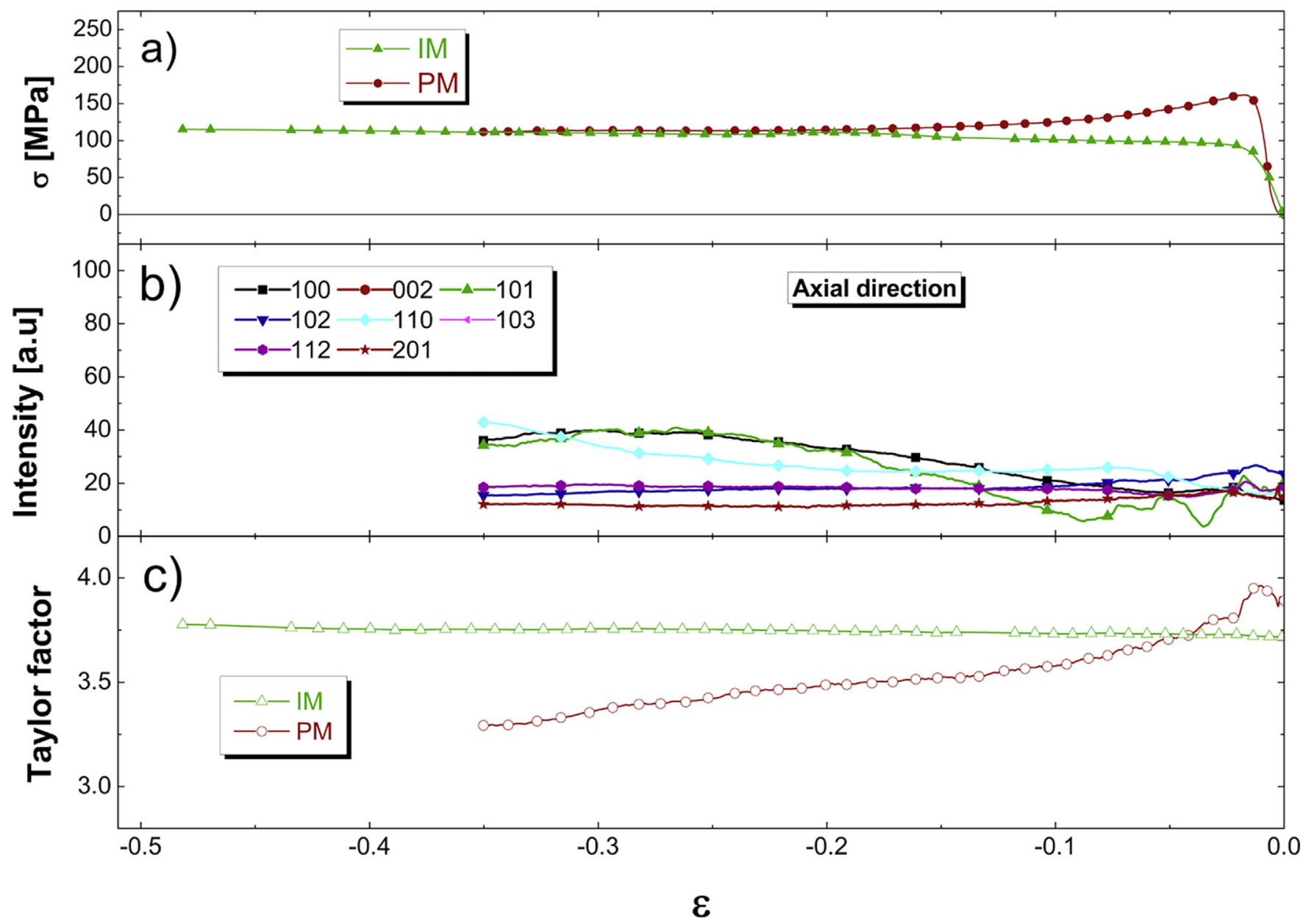

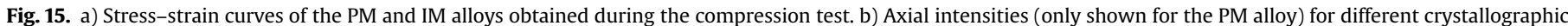
planes of the $\alpha$-phase (b) and c) Taylor factors for both PM and IM alloys.

to separate them. Nevertheless, it can be assumed that at up to I $\varepsilon \mid=0.07$ the crystallite size does not undergo significant variation (from the AS-plots only grain rotation is observed). Consequently, the dislocation density remains as main contribution factor to the FWHM and its reduction for $\alpha-110$ and $\alpha-101$ can be connected to preferentially annihilation of dislocations through these slip planes. This softening process can be roughly quantified as $\sim 10 \%$ (FWHM at the peak stress divided by the FWHM at $|\mathcal{E}| \sim 0.05$ in Fig. 16c). The Taylor factor reduction and the annihilation dislocation can be considered responsible of the $20 \%$ and $10 \%$, respectively, of the total softening observed ( 30\%).

\section{Conclusions}

The following conclusions can be drawn from the results obtained:

1. The higher peak stress exhibited by the Ti662 powder metallurgy alloy is a consequence of the random lamellae orientation and large size of the $\alpha$-lamellae, which provokes a less favourable number of colony- $\alpha$ conveniently orientated for slip activation. This results in a larger Taylor factor, reflected by the higher deviatoric $\alpha$-stresses at the maximum stress.

2 . $\beta$-phase plastifies at very small deformation in both alloys and deformation types, acting merely as a load transfer agent.
3. The lamellar $\alpha$-phase in the Ti662 powder metallurgy alloy deforms by rotation during the hot deformation. This rotation is the consequence of both geometrical reorientation of the lamellae and crystallographic rotation within the lamellae. At strains larger than $0.06, \alpha$-prismatic texture is developed.

4. The $\beta$-phase in the Ti662 powder metallurgy alloy deforms by increase of misorientation within grains and possible subgrain formation, in agreement with the behaviour of high stacking fault energy phases.

5. The Taylor factor exhibits a decrease as compressive deformation proceeds for the Ti662 powder metallurgy alloy that can be quantitatively calculated using the crystallographic data obtained by the in situ high energy synchrotron radiation measurements.

6. The total softening observed for the Ti662 powder metallurgy alloy during the compression test is $\sim 30 \%$ and can be ascribed to a reduction of the Taylor factor in $\sim 20 \%$ and to annihilation of dislocations through prismatic $\alpha-110$ and pyramidal $\alpha-101$ planes in $\sim 10 \%$.

\section{Acknowledgements}

The financial support from the "K-Project for Non-Destructive Testing and Tomography Plus" - COMET - Program of the Austrian Research Promotion Agency (FFG), Grant No. 843540, financed by 


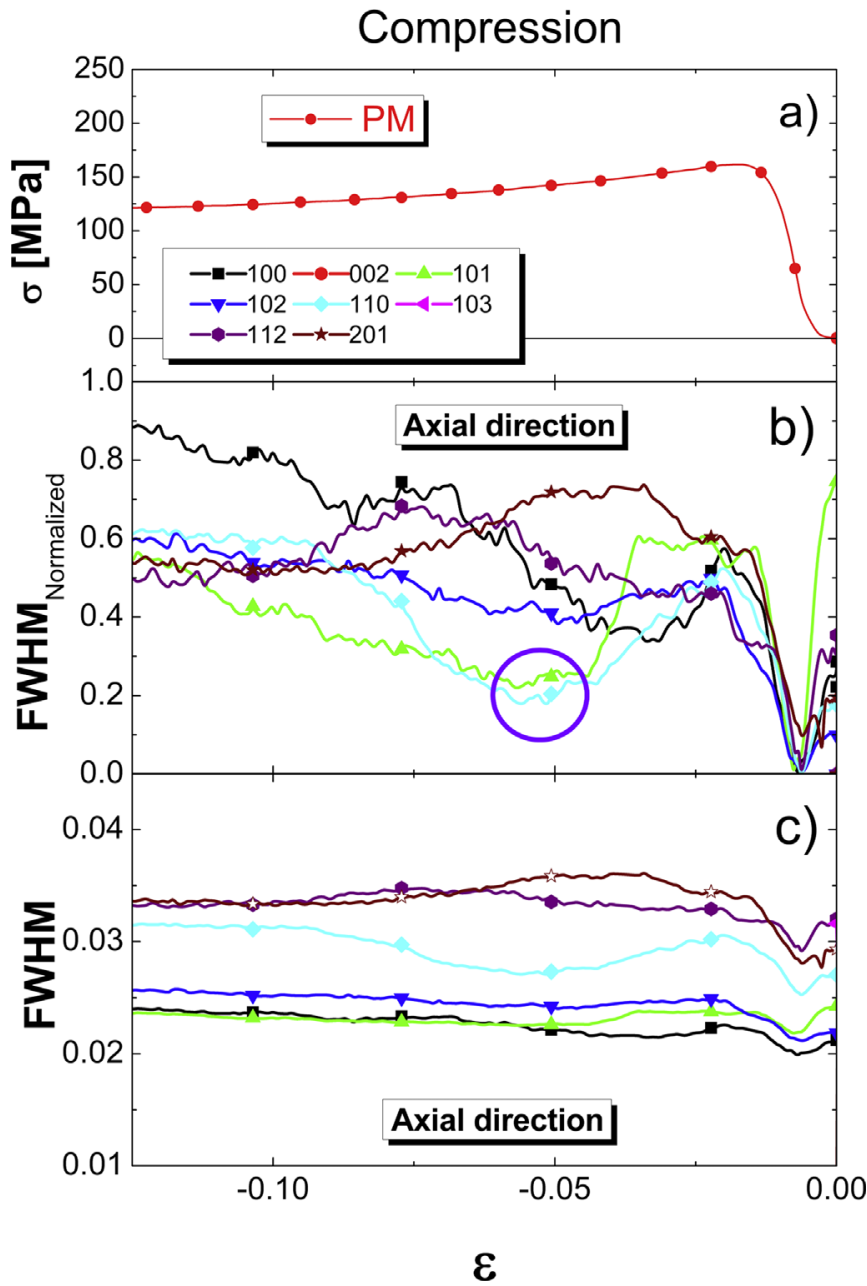

Fig. 16. a) Stress-strain curve up to $\varepsilon=-0.125$ of the PM alloy obtained during the compression test. Normalized (b) and absolute (c) FWHM values in axial direction for different crystallographic planes of the $\alpha$-phase.

FFG and the Governments of Upper Austria and Styria is acknowledged. The work was partially supported by FWF (Austrian Science Fund) project P22238-N22 and P27471-N19. The authors would like to thank the allocation of beamline at 1) the ID15B beamline (ESRF) in the framework of proposal MA727, 2) the Beamline Harwi-II (DESY) and 3) the P07-HEMS beamline of Petra III (DESY). Thomas Lippmann from Institute of Materials Research (Helmholtz-Zentrum Geesthacht) is also acknowledged for the collaboration during the HEXRD experiments.

The University Service for Transmission Electron Microscopy (USTEM) of the Vienna University of Technology is acknowledged for the provision of the SEM microscope.

\section{References}

[1] C. Leyens, M. Peters, Titanium and Titanium Alloys, Wiley-VCH, Weinheim, 2003.

[2] C. Poletti, L. Germain, F. Warchomicka, M. Dikovits, S. Mitsche, Unified description of the softening behavior of beta-metastable and alpha + beta titanium alloys during hot deformation, Mater. Sci. Eng. A 651 (2016) 280-290.

[3] M.R. Daymond, P.J. Withers, A synchrotron radiation study of transient internal strain changes during the early stages of thermal cycling in an $\mathrm{Al} / \mathrm{SiCW}$ MMC, Scr. Mater. 35 (1996) 1229-1234.

[4] A. Lodini, in: M.E. Fitzpatrick, A. Lodini (Eds.), Analysis of Residual Stress by Diffraction using Neutron and Synchrotron Radiation, Taylor\&Francis, London, 2003, pp. 47-59.

[5] M.T. Hutchings, P.J. Withers, T.M. Holden, T. Lorentzen, Introduction to the
Characterization of Residual Stress by Neutron Diffraction, Taylor\&Francis, Boca Raton, 2005.

[6] W. Reimers, in: W. Reimers, A.R. Pyzalla, A. Schreyer, H. Clemens (Eds.), Neutrons and Synchrotron Radiation in Engineering Materials Science, WileyVCH, Weinheim, 2008, pp. 115-135.

[7] K.-D. Liss, K. Yan, Thermo-mechanical processing in a synchrotron beam, Mater. Sci. Eng. A 528 (2010) 11-27.

[8] C.J. Bettles, M.A. Gibson, A.W. Stevenson, D. Tomus, P.A. Lynch, In-situ observation of strain evolution in CP-Ti during uniaxial tensile loading, Nucl. Instrum. Methods A 619 (2010) 302-305.

[9] J.V. Bernier, J.-S. Park, A.L. Pilchak, M.G. Glavicic, M.P. Miller, Measuring stress distributions in Ti-6Al-4V using synchrotron X-ray diffraction, Metall. Mater. Trans. A 39 (2008) 3120-3133.

[10] A.M. Stapleton, S.L. Raghunathan, I. Bantounas, H.J. Stone, T.C. Lindley, D. Dye, Evolution of lattice strain in Ti-6Al-4V during tensile loading at room temperature, Acta Mater. 56 (2008) 6186-6196.

[11] J.L.W. Warwick, N.G. Jones, K.M. Rahman, D. Dye, Lattice strain evolution during tensile and compressive loading of CP Ti, Acta Mater. 60 (2012) 6720-6731.

[12] S.L. Raghunathan, A.M. Stapleton, R.J. Dashwood, M. Jackson, D. Dye, Micromechanics of Ti-10V-2Fe-3Al: in situ synchrotron characterisation and modelling, Acta Mater. 55 (2007) 6861-6872.

[13] J.R. Cho, D. Dye, K.T. Conlon, M.R. Daymond, R.C. Reed, Intergranular strain accumulation in a near-alpha titanium alloy during plastic deformation, Acta Mater. 50 (2002) 4847-4864.

[14] J.L.W. Warwick, J. Coakley, S.L. Raghunathan, R.J. Talling, D. Dye, Effect of texture on load partitioning in Ti-6Al-4V, Acta Mater. 60 (2012) 4117-4127.

[15] D. Gloaguen, G. Oum, V. Legrand, J. Fajoui, S. Branchu, Experimental and theoretical studies of intergranular strain in an alpha titanium alloy during plastic deformation, Acta Mater. 61 (2013) 5779-5790.

[16] D. Gloaguen, G. Oum, V. Legrand, J. Fajoui, M.J. Moya, T. Pirling, W. Kockelmann, Intergranular strain evolution in titanium during tensile loading: neutron diffraction and polycrystalline model, Metall. Mater. Trans. A 46 (2015) 5038-5046.

[17] J.L.W. Warwick, N.G. Jones, I. Bantounas, M. Preuss, D. Dye, In situ observation of texture and microstructure evolution during rolling and globularization of Ti-6Al-4V, Acta Mater. 61 (2013) 1603-1615.

[18] S.L. Semiatin, T.R. Bieler, Effect of texture and slip mode on the anisotropy of plastic flow and flow softening during hot working of Ti-6Al-4V, Metall. Mater. Trans. A 32 (2001) 1787-1799.

[19] S.L. Semiatin, T.R. Bieler, The effect of alpha platelet thickness on plastic flow during hot working of Ti-6Al-4V with a transformed microstructure, Acta Mater. 49 (2001) 3565-3573.

[20] S.L. Semiatin, V. Seetharaman, I. Weiss, Flow behavior and globularization kinetics during hot working of Ti-6Al-4V with a colony alpha microstructure, Mater. Sci. Eng. A 263 (1999) 257-271.

[21] R.M. Miller, T.R. Bieler, S.L. Semiatin, Flow softening during hot working of Ti$6 \mathrm{Al}-4 \mathrm{~V}$ with a lamellar colony microstructure, Scr. Mater. 40 (1999) 1387-1393.

[22] E.B. Shell, S.L. Semiatin, Effect of initial microstructure on plastic flow and dynamic globularization during hot working of Ti-6Al-4V, Metall. Mater. Trans. A 30 (1999) 3219-3229.

[23] R. Boyer, G. Welsch, E.W. Collings, Material Properties Handbook. Titanium Alloys, ASM International, Ohio, 1994.

[24] C. Poletti, H.P. Degischer, S. Kremmer, W. Marketz, Processing maps of Ti662 unreinforced and reinforced with TiC particles according to dynamic models, Mater. Sci. Eng. A 486 (2008) 127-137.

[25] 〈http://www.dynamettechnology.com/〉.

[26] F. Beckmann, T. Dose, T. Lippmann, L. Lottermoser, R.V. Martins, A. Schreyer, The new materials science beamline HARW-II at DESY, AIP Conf. Proc. 879 (2007) 746-749.

[27] A.P. Hammersley, S.O. Svensson, M. Hanfland, A.N. Fitch, D. Häusermann, Twodimensional detector software: from real detector to idealized image or twotheta scan, High Press. Res. 14 (1996) 235-248.

[28] G. Garcés, G. Bruno, A. Wanner, Residual stresses in deformed random-planar aluminium/saffil ${ }^{\mathbb{R}}$ short-fibre composites, Mater. Sci. Eng. A 417 (2006) 73-81.

[29] G. Lütjering, J.C. Williams, Titanium, Springer, Heidelberg, 2007.

[30] S. Fréour, D. Gloaguen, M. Francois, A. Perronnet, R. Guillén, Determination of single-crystal elasticity constants in a cubic phase within a multiphase alloy: $\mathrm{X}$-ray diffraction measurements and inverse-scale transition modelling, J. Appl. Crystallogr. 38 (2005) 30-37.

[31] M. Ledbetter, H. Ogi, S. Kai, S. Kim, M. Hirao, Elastic constants of body-centered-cubic titanium monocrystals, J. Appl. Phys. 95 (2004) 4642-4644.

[32] H. Wern, R. Johannes, H. Walz, Dependence of the X-ray elastic constants on the diffraction plane, Phys. Status Solidi B 206 (1998) 545-557.

[33] E. Kröner, Berechnung der elastischen Konstanten des Vielkristalls aus den Konstanten des Einkristalls, Z. Phys. 151 (1958) 504-518.

[34] L. Lutterotti, S. Matthies, H.-R. Wenk, A.S. Schultz, J.W. Richardson, Combined texture and structure analysis of deformed limestone from time-of-flight neutron diffraction spectra, J. Appl. Phys. 81 (1997) 594-600.

[35] H.-R. Wenk, L. Lutterotti, S. Vogel, Texture analysis with the new HIPPO TOF diffractometer, Nucl. Instrum. Methods A 515 (2003) 575-588.

[36] K.-D. Liss, T. Schmoelzer, K. Yan, M. Reid, M. Peel, R. Dippenaar, H. Clemens, In situ study of dynamic recrystallization and hot deformation behavior of a multiphase titanium aluminide alloy, J. Appl. Phys. 106 (2009) 113526.

[37] ImageJ, available in 〈http://rsbweb.nih.gov/ij/〉. 
[38] R. Armstrong, I. Codd, R.M. Douthwaite, N.J. Petch, Philos. Mag. 7 (1962) $45-48$.

[39] J.D. Eshelby, Phys. Status Solidi 3 (1963) 2057-2060.

[40] F. Warchomicka, C. Poletti, M. Stockinger, T. Henke, Microstructure evolution during hot deformation of Ti-6Al-4V double cone specimens, Int. J. Mater. Form. 3 (2010) 215-218.

[41] F. Warchomicka, C. Poletti, M. Stockinger, Study of the hot deformation behavior in Ti-5Al-5Mo-5V-3Cr-1Zr, Mater. Sci. Eng. A 528 (2011) 8277-8285.

[42] S. Mironov, M. Murzinova, S. Zherebtsov, G.A. Salishchev, S.L. Semiatin, Microstructure evolution during warm working of Ti-6Al-4V with a colony- $\alpha$ microstructure, Acta Mater. 57 (2009) 2470-2481.

[43] G. Requena, D. Canelo-Yubero, G. Fiedler, G. Garcés, C. Poletti, In-Situ Diffraction During Deformation and Synchrotron Tomography of Light Alloys,
MECA SENS VI, Hamburg, 2011.

[44] S. Zherebtsov, M. Murzinova, G. Salishchev, S.L. Semiatin, Spheroidization of the lamellar microstructure in Ti-6Al-4V alloy during warm deformation and annealing, Acta Mater. 59 (2011) 4138-4150.

[45] K.-D. Liss, U. Garbe, H. Li, T. Schambron, J.D. Almer, K. Yan, In situ observation of dynamic recrystallization in the bulk of zirconium alloy, Adv. Eng. Mater. 11 (2009) 637-640.

[46] S. Roy, S. Suwas, The influence of temperature and strain rate on the deformation response and microstructural evolution during hot compression of a titanium alloy Ti-6Al-4V-0.1B, J. Alloy. Compd. 548 (2013) 110-125.

[47] R. Fernández, G. Bruno, G. González-Doncel, Residual stress evolution with compressive plastic deformation in 6061 Al-15 vol.\% SiCw composites as studied by neutron diffraction, Mater. Sci. Eng. A 403 (2005) 260-268. 